ARTICLE

\title{
Global distribution patterns of marine nitrogen- fixers by imaging and molecular methods
}

Juan José Pierella Karlusich ${ }^{1,2}$, Eric Pelletier ${ }^{2,3}$, Fabien Lombard (1D ${ }^{2,4,5}$, Madeline Carsique ${ }^{1}$, Etienne Dvorak (D) 1 , Sébastien Colin 6,7,8, Marc Picheral ${ }^{2,4}$, Francisco M. Cornejo-Castillo (10 7, Silvia G. Acinas (1) ${ }^{9}$, Rainer Pepperkok 2,6 , Eric Karsenti ${ }^{1,2,6}$, Colomban de Vargas ${ }^{2,7}$, Patrick Wincker (i] ${ }^{2,3}$, Chris Bowler ${ }^{1,2 \bowtie} \&$ Rachel A. Foster (1) ${ }^{10 \otimes}$

Nitrogen fixation has a critical role in marine primary production, yet our understanding of marine nitrogen-fixers (diazotrophs) is hindered by limited observations. Here, we report a quantitative image analysis pipeline combined with mapping of molecular markers for mining $>2,000,000$ images and >1300 metagenomes from surface, deep chlorophyll maximum and mesopelagic seawater samples across 6 size fractions $(<0.2-2000 \mu \mathrm{m})$. We use this approach to characterise the diversity, abundance, biovolume and distribution of symbiotic, colony-forming and particle-associated diazotrophs at a global scale. We show that imaging and PCR-free molecular data are congruent. Sequence reads indicate diazotrophs are detected from the ultrasmall bacterioplankton $(<0.2 \mu \mathrm{m})$ to mesoplankton $(180-2000 \mu \mathrm{m})$ communities, while images predict numerous symbiotic and colony-forming diazotrophs (>20 $\mu \mathrm{m})$. Using imaging and molecular data, we estimate that polyploidy can substantially affect gene abundances of symbiotic versus colony-forming diazotrophs. Our results support the canonical view that larger diazotrophs $(>10 \mu \mathrm{m})$ dominate the tropical belts, while unicellular cyanobacterial and non-cyanobacterial diazotrophs are globally distributed in surface and mesopelagic layers. We describe co-occurring diazotrophic lineages of different lifestyles and identify high-density regions of diazotrophs in the global ocean. Overall, we provide an update of marine diazotroph biogeographical diversity and present a new bioimagingbioinformatic workflow.

\footnotetext{
${ }^{1}$ Institut de Biologie de I'ENS (IBENS), Département de biologie, École normale supérieure, CNRS, INSERM, Université PSL, Paris, France. ${ }^{2}$ CNRS Research Federation for the study of Global Ocean Systems Ecology and Evolution, FR2022/Tara Oceans GOSEE, Paris, France. ${ }^{3}$ Génomique Métabolique, Genoscope, Institut François Jacob, CEA, CNRS, Univ Evry, Université Paris-Saclay, Evry, France. ${ }^{4}$ Sorbonne Universités, CNRS, Laboratoire d'Océanographie de Villefranche (LOV), Villefranche-sur-Mer, France. ${ }^{5}$ Institut Universitaire de France (IUF), Paris, France. ${ }^{6}$ European Molecular Biology Laboratory, Heidelberg, Germany. ${ }^{7}$ Sorbonne Université, CNRS, Station Biologique de Roscoff, UMR 7144, ECOMAP, Roscoff, France. ${ }^{8}$ Max Planck Institute for Developmental Biology, Tübingen, Germany. ${ }^{9}$ Department of Marine Biology and Oceanography, Institut de Ciènces del Mar, CSIC, Barcelona, Spain.

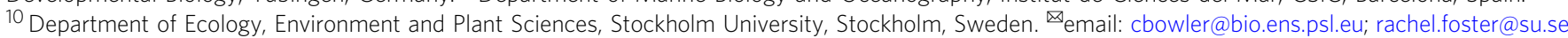


A pproximately half of global primary production occurs in the oceans ${ }^{1}$, fueling marine food webs, plankton decomposition and sequestration of fixed carbon to the ocean interior. Marine primary production is often limited by nitrogen (N) in vast expanses of the open ocean $(\sim 75 \%$ of surface ocean $)^{2,3}$. In these regions, the biological reduction of di-nitrogen gas $\left(\mathrm{N}_{2}\right)$ to bioavailable $\mathrm{N}$, a process called biological $\mathrm{N}_{2}$ fixation (BNF), is a critical source of new $\mathrm{N}$ to the ecosystem and ultimately controls the uptake and sequestration of carbon dioxide $\left(\mathrm{CO}_{2}\right)$ on geologic time scales ${ }^{4-6}$.

In the upper sunlit ocean, it was traditionally thought that BNF was largely restricted to the subtropical and tropical gyres and mediated by a few groups of larger sized $\mathrm{N}_{2}$-fixing (diazotrophic) cyanobacteria and holobionts $(>10 \mu \mathrm{m})$ : the colony-forming nonheterocystous Trichodesmium spp., and heterocystous cyanobacterial (Richelia intracellularis and Calothrix rhizosoleniae, hereafter Richelia and Calothrix, respectively) symbionts of diatoms (diatom-diazotroph associations; DDAs) ${ }^{7}$. More recently, unicellular cyanobacteria (UCYN) have been detected in environmental samples outside the tropical belts by qPCR targeting the BNF marker gene nif $H^{8}$. One of these $\mathrm{N}_{2}$-fixing UCYN groups is Candidatus Atelocyanobacterium thalassa (hereafter UCYN-A). Three UCYN-A lineages (A-1, A-2, A-3) live in symbiosis with a small single celled eukaryote (haptophyte) ${ }^{9-11}$. UCYN-B is another unicellular group that is most closely related to Crocosphaera watsonii (hereafter Crocosphaera). UCYN-B lives singly, colonially or in symbioses with a large chain-forming diatom (Climacodium frauenfeldianum $)^{12-14}$. UCYN-C is the third marine unicellular group identified thus far by nifH sequence, and is most closely related to the free-living unicellular diazotroph Cyanothece sp. ATCC $51142^{15}$, and less studied. Finally, noncyanobacterial diazotrophs (NCDs), including Archaeal and Bacterial lineages, co-occur with the cyanobacterial diazotrophs in the surface ocean and additionally below the photic layer. The distribution and in situ activity of NCDs are poorly constrained and difficult to estimate ${ }^{16-18}$.

The first global ocean database of diazotrophs was compiled for the MARine Ecosystem DATa (MAREDAT) project ${ }^{19}$. It includes cell counts for diazotrophs that can be identified by microscopy (Trichodesmium, Richelia, and Calothrix), as well as nifH qPCR datasets which additionally cover UCYN-A, UCYN-B, and UCYN-C (Supplementary Fig. S1a). A recent update of the MAREDAT dataset resulted in more than doubling of the nifH observations ${ }^{20}$. However, both MAREDAT and the updated version still have low coverage in vast regions of the global ocean (Supplementary Fig. S1a). Several of these poorly sampled areas were sampled during the Tara Oceans circumnavigation (2009-2013) $)^{21}$ (Supplementary Fig. S1b).

Tara Oceans collected discrete size fractions of plankton using a serial filtration system ${ }^{21}$; some samples were used to generate parallel molecular and imaging datasets. The Tara Oceans gene catalog from samples enriched in free-living prokaryotes is based on the assembly of metagenomes and is highly comprehensive $\mathrm{e}^{22,23}$. However, the larger plankton size fractions $(>0.8 \mu \mathrm{m})$ enriched in eukaryotes are genomically much more complex, and thus current Tara Oceans gene catalogs from these fractions are based only on poly-A-tailed eukaryotic RNA ${ }^{24,25}$. Hence, the prokaryotes from these larger size fractions have been unstudied and are limited to specific taxa based on these poly-A assembled sequences ${ }^{26-28}$, and thus the signal is difficult to interpret quantitatively ${ }^{29}$. The Tara Oceans imaging dataset ${ }^{30}$ is also underutilized, especially due to the lack of well-established workflows. Overall, the cyanobacterial diazotrophs, especially those with diverse lifestyles (colonial, symbiotic, chain formers), have been poorly characterized (with the exception of UCYN-A ${ }^{11,16,22,26,28,31}$ ).
Here, we report the diversity, abundance, and distribution of symbiotic, colony-forming, and particle-associated diazotrophs in the global ocean by mining $>1300$ metagenomes $^{22,24,25}$ and $>2,000,000$ high-throughput images from Tara Oceans. We use the single-copy core bacterial gene $r e c A^{32}$ to quantify the bacterial community in each metagenome; thus the read abundance ratio of nifH/recA provides an estimate for the relative contribution of diazotrophs. In parallel, we train an image classification model and utilized it with images from an Underwater Vision Profiler $(\mathrm{UVP})^{33}$ and confocal microscopy ${ }^{30}$ to generate a versatile analytical pipeline from images to genomics and genomics to images. We find a remarkable congruence between the image and genebased analyses, and several new 'hotspots' for diazotrophs are identified for the first time to our knowledge. Accordingly, diazotrophs are globally distributed and present in all size fractions, even among ultrasmall bacterioplankton $(<0.22 \mu \mathrm{m})$. Other unexpected results include the detection of nifH sequences similar to freshwater obligate symbionts in multiple and distant ocean basins, a general lack of UCYN nifH sequences in the surface ocean, ubiquitous detection of NCDs, and a consistent cooccurrence of multiple cyanobacterial diazotrophs (from both images and genes) in several locations. Overall, this work provides an updated composite of diazotroph biogeography in the global ocean and the environmental factors that shape these patterns.

\section{Results and discussion}

Diazotroph abundance and biovolume based on imaging methods. We first used machine learning tools (see "Methods" 30 ) to search for diazotrophs in the Tara Oceans high-throughput confocal imaging dataset derived from 61 samples of the $20-180$ $\mu \mathrm{m}$ plankton size fraction collected at 48 different sampling locations (Supplementary Fig. S2). More than 400 images of DDAs and almost 600 images of Trichodesmium-free filaments were predicted (Figs. 1 and 2; https://www.ebi.ac.uk/biostudies/ studies/S-BSST529); all images were from the tropical and subtropical regions and consistent with the molecular analyses (see later). The same image recognition searches were performed on the confocal microscopy images from the 5-20 $\mu \mathrm{m}$ size fraction ${ }^{30}$, which covers 75 samples from 51 stations. These searches detected only 8 images of short Trichodesmium filaments and 4 single Hemiaulus-Richelia symbiotic cells. Thus our observations are in agreement with earlier studies showing that most filaments are collected by their length rather than their diameter during sampling ${ }^{34}$.

Several new locations to our knowledge not previously reported in diazotroph databases were identified (see below; Fig. 3, Supplementary Figs. S3 and S4). In addition, we detected colonies of Crocosphaera-like cells and others living in the more rarely reported diatom Climacodium ${ }^{12-14}$. Notably, a few Crocosphaera cells (1-2 cells) were detected by their strong phycoerythrin signal emitted in the alexa 546 channel while both the Crocosphaera cells and chloroplast of each Climacodium host emitted autofluorescence signals in the red channel $(638 \mathrm{~nm})$, demonstrating the combination of signals is a key attribute in detection of inconspicuous plankton by the image recognition model (Fig. 1).

Ranges in abundances based on image analyses for the 3 main DDAs: Hemiaulus-Richelia, Rhizosolenia-Richelia, and Chaetoceros-Calothrix, were low and are representative of background densities (e.g., 1.5-20 symbiotic cells $\mathrm{L}^{-1}$ ) (Fig. 3 and Supplementary Fig. S3a). The low densities and detection, especially Chaetoceros-Calothrix which can form long chains (>50 cells chain ${ }^{-1}$ ) and the larger Rhizosolenia-Richelia symbioses, were not surprising given the $180 \mu \mathrm{m}$ sieve used in the 


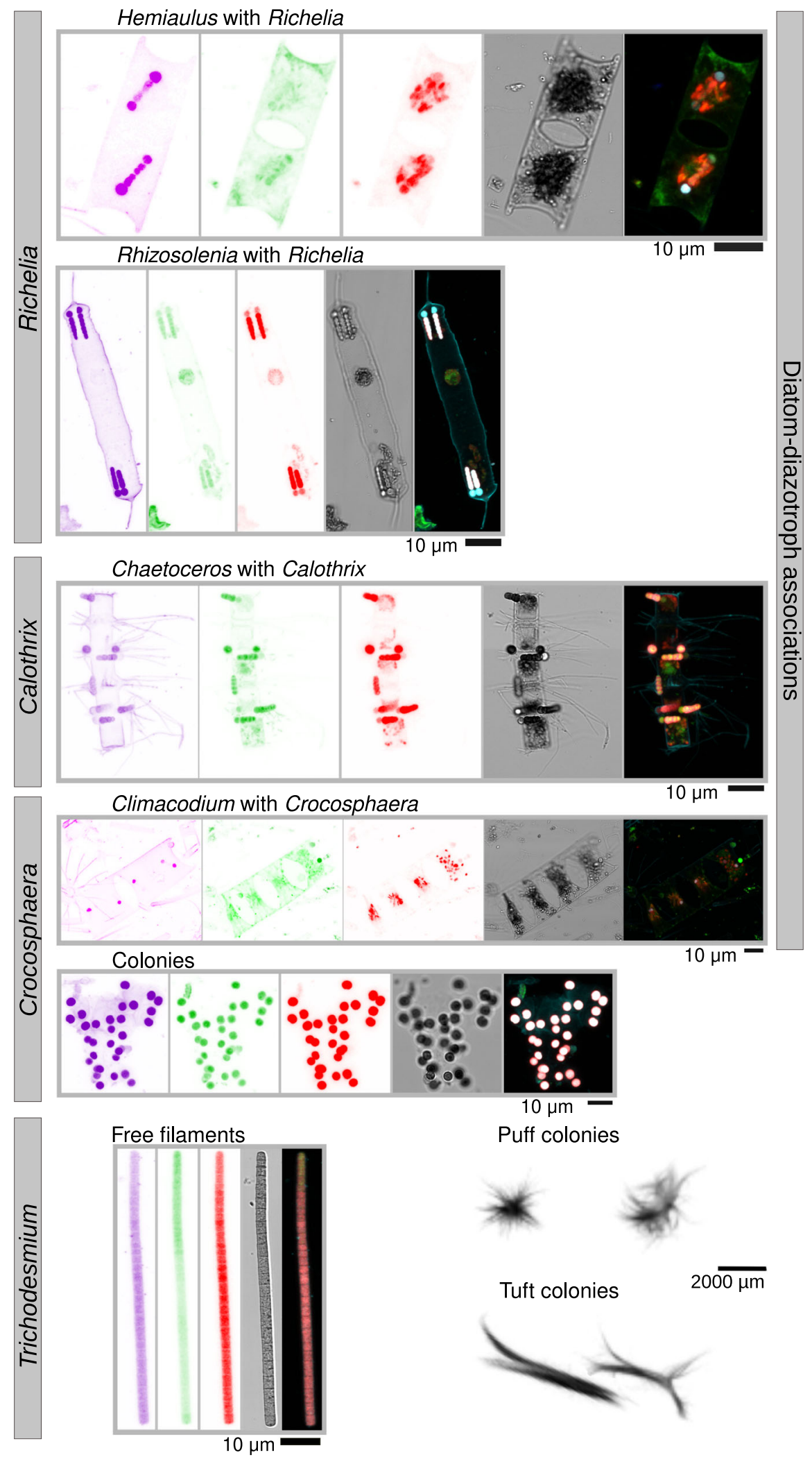

sample processing. Although Hemiaulus-Richelia was the most frequently detected, its chains were often short (1-2 cells), and sometimes cell integrity was compromised (i.e., broken frustules; poor autofluorescence). Variation in the number and length of the symbiont filaments (trichomes) was also observed and was dependent on which host the Richelia/Calothrix was associated (Fig. 2), consistent with previous observations ${ }^{13}$. Free Richelia and Calothrix filaments were also found (Supplementary Fig. S5), which are less often reported in the literature ${ }^{35}$, but are not unexpected for facultative symbionts 36,37 .

DDAs and free Richelia/Calothrix filaments were broadly distributed and detected in several new locations ${ }^{19,20}$ to our knowledge, including the Indian Ocean (IO), western South Atlantic Ocean (SAO), the South Pacific gyre, and the Pacific side 
Fig. 1 Imaging observations of diazotrophs in Tara Oceans samples. Images were obtained by environmental high content fluorescence microscopy (eHCFM; ref. ${ }^{30}$ ), with the exception of Trichodesmium colonies, which were detected in situ using an Underwater Vision Profiler 5 (UVP5; ref. ${ }^{33}$ ). From left to right, the displayed channels for each micrograph correspond to: cell surface (cyan, AlexaFluor 546), cellular membranes (green, DiOC6), chlorophyll autofluorescence (red), the bright field, and the merged channels. The displayed Hemiaulus-Richelia association was detected at station TARA_80 in the South Atlantic Ocean, Rhizosolenia-Richelia at TARA_53 in the Indian Ocean, Chaetoceros-Calothrix at TARA_131 (ALOHA) in the North Pacific Ocean, Climacodium-Croscophaera at TARA_140 in the North Pacific Ocean, the Croscophaera-like colony at TARA_53 in the Indian Ocean, the Trichodesmium filament at TARA_42 in the Indian Ocean, and the Trichodesmium colonies at TARA_141 and TARA_142 in the North Atlantic Ocean. Each micrograph is representative of the following number of images obtained in the current study: 350 Hemiaulus-Richelia, 56 Rhizosolenia-Richelia, 8 Chaetoceros-Calothrix, 1 Climacodium-Crocosphaera, 150 Crocosphaera-like colonies, 605 Trichodesmium-free filaments, 115 puff and 95 tuft colonies of Trichodesmium.
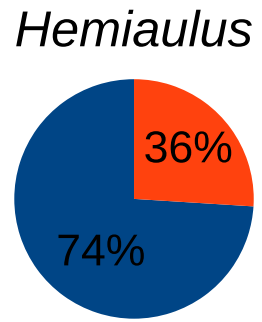

\# Richelia

filaments

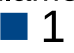

2

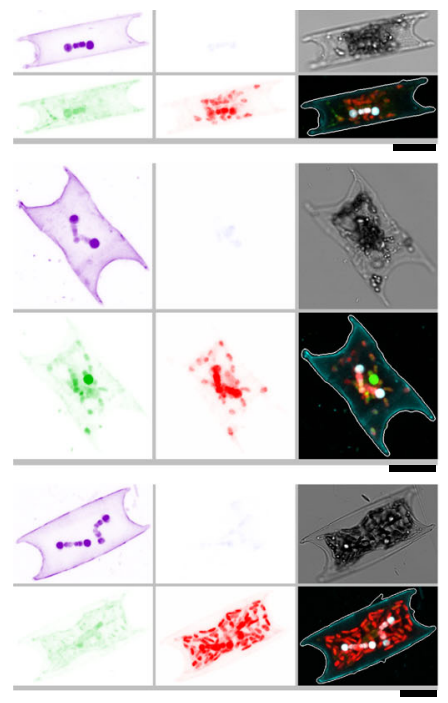

Rhizosolenia

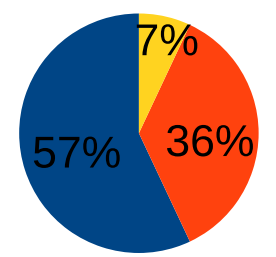

\# Richelia filaments
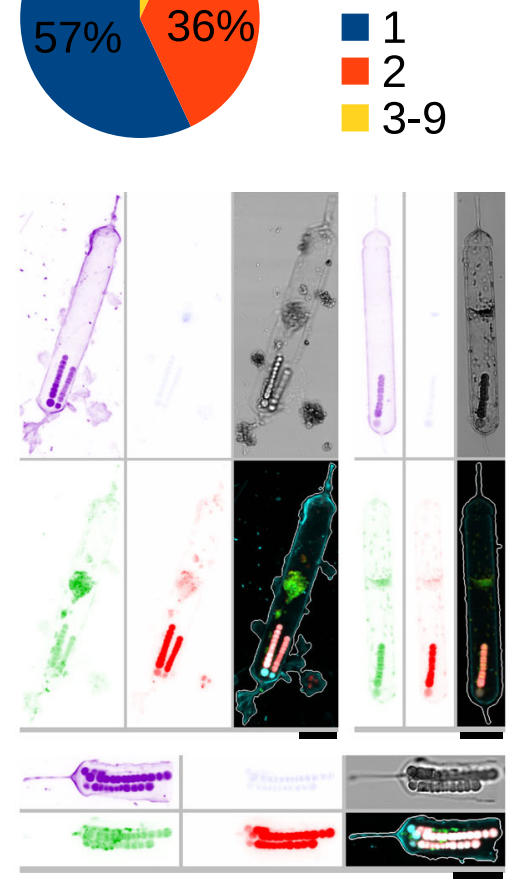

\section{Chaetoceros}
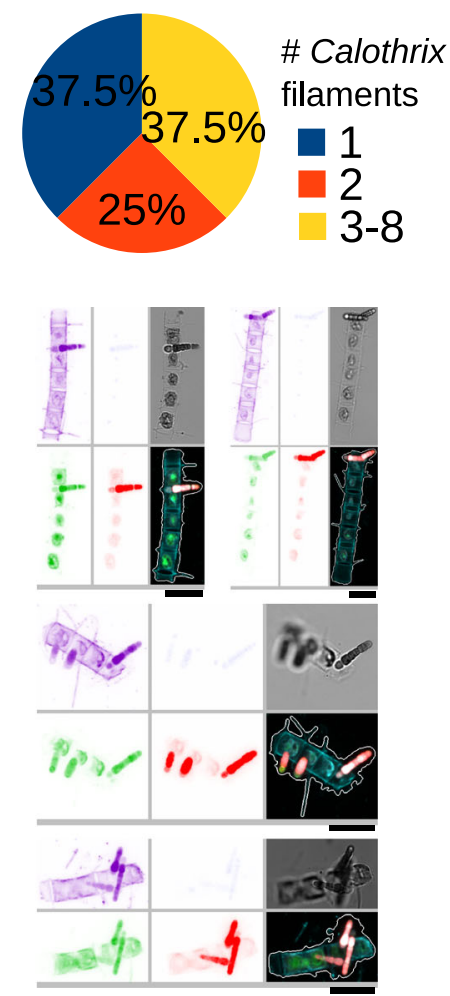

Fig. 2 Variation in the number of Richelia/Calothrix filaments among the diatom-diazotroph associations observed by high-throughput confocal microscopy. Examples of images are shown. Clockwise from top-left, the displayed channels for each micrograph correspond to: cell surface (cyan, AlexaFluor 546 dye), DNA (blue, Hoechst dye), the bright field, cellular membranes (green, DiOC6 dye), chlorophyll autofluorescence (red), and the merged channels. The size bar at the bottom left of each microscopy image corresponds to $10 \mu \mathrm{m}$.

of the Panama Canal (Supplementary Figs. S3 and S5). DDAs were concentrated in the surface, with the exception of two deeper samples of Hemiaulus-Richelia, with densities as high as in the surface. The two exceptions were the 108-m depth sample from the Hawaii Ocean Time Series station ALOHA (A LongTerm Oligotrophic Habitat Assessment; TARA_131; North Pacific Subtropical Gyre) and the 38-m depth one from TARA_143 (Gulf Stream, North Atlantic) (Fig. 3b). Seasonal blooms of DDAs are well known at station ALOHA, with observations of DDAs in moored sediment traps below the photic zone $^{38-40}$. However, observations of symbiotic diatoms in the Gulf Stream are more rare ${ }^{41}$.

We observed densities of 1-40 Trichodesmium-free filaments $\mathrm{L}^{-1}$. Similar to the DDAs, long free filaments of Trichodesmium were likely undersampled due to the collection and processing (35\% of them are $>180 \mu \mathrm{m}$ in length). Free filaments of Trichodesmium co-occurred with DDAs in most stations from the IO and North Pacific Ocean (NPO) (Fig. 3a and Supplementary Fig. S4), and they were also observed at sites where DDAs were not detected, such as in the Pacific North Equatorial Current (TARA_136). Tens to hundreds of Trichodesmium filaments often aggregate into fusiform-shaped colonies usually referred to as 'tufts' or 'rafts' or round-shaped colonies called 'puffs' (from $200 \mu \mathrm{m}$ to $5 \mathrm{~mm}$ ) (Fig. 1). These dimensions were detectable and quantifiable by in situ imaging using the UVP5 ${ }^{33}$ (Fig. 3 and Supplementary Fig. S4a). A total of 220 images were clearly curated as tuft or puff colonies, with the major axis ranging from 1 to $10 \mathrm{~mm}$ and the minor axis from 0.4 to $4 \mathrm{~mm}$ (https://www.ebi.ac.uk/biostudies/studies/SBSST529). Our stringent annotation probably underestimated Trichodesmium colony abundances (see below the correlation with metagenomes). Colony densities were more prevalent in the NAO and NPO, while free filament densities were more abundant in the IO (Fig. 3a and Supplementary Fig. S4a), probably related to the enhanced colony formation of Trichodesmium under nutrient limitation (Supplementary 

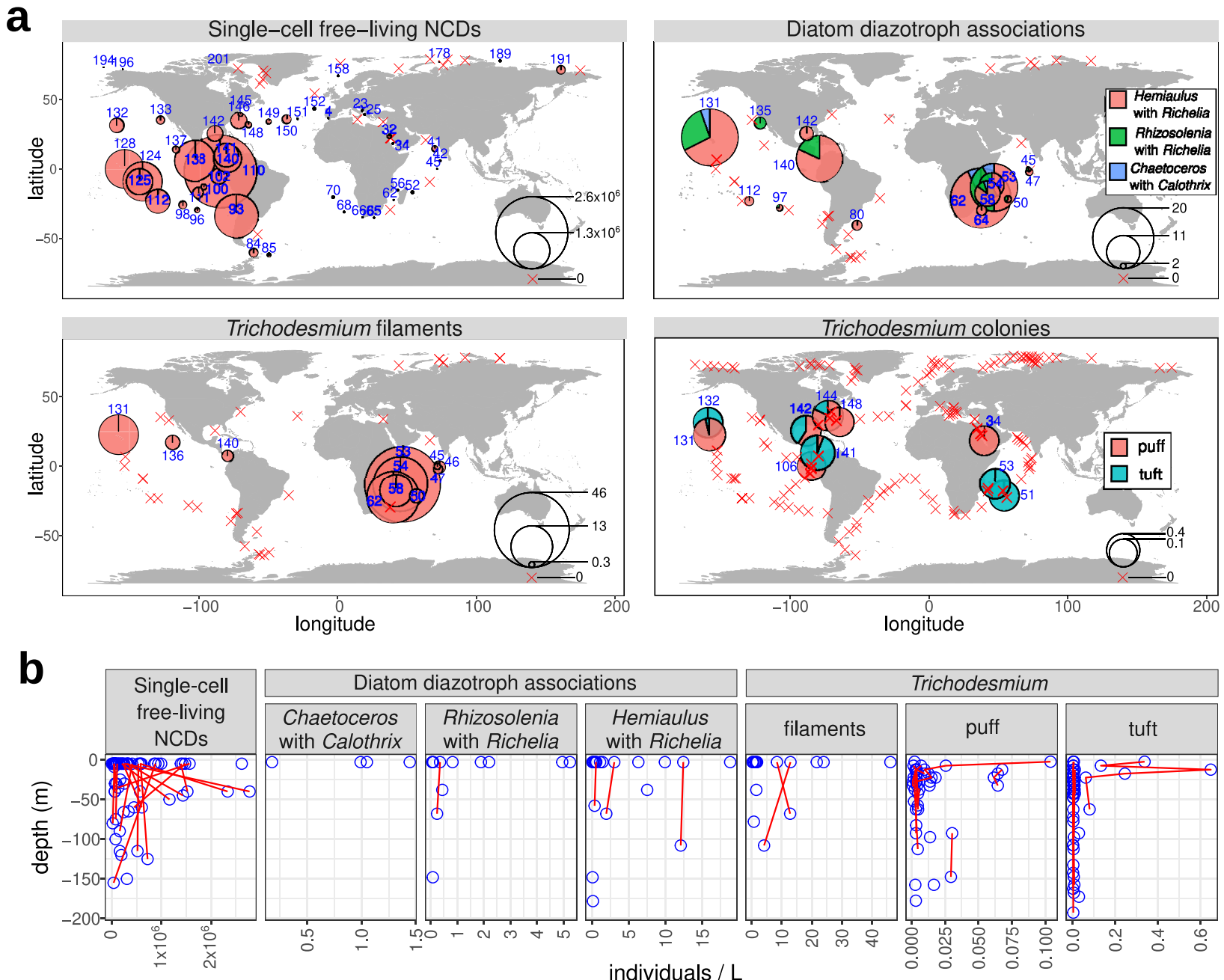

C Single-cell

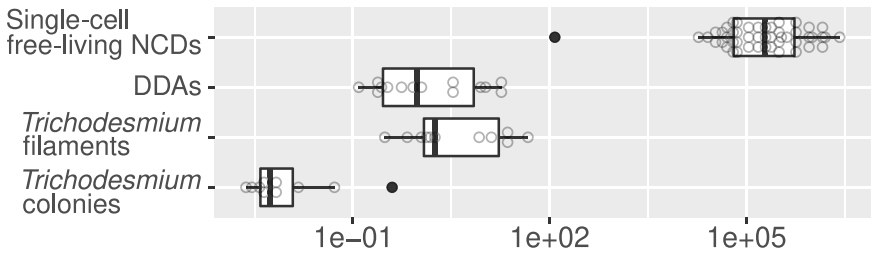

Individuals / L
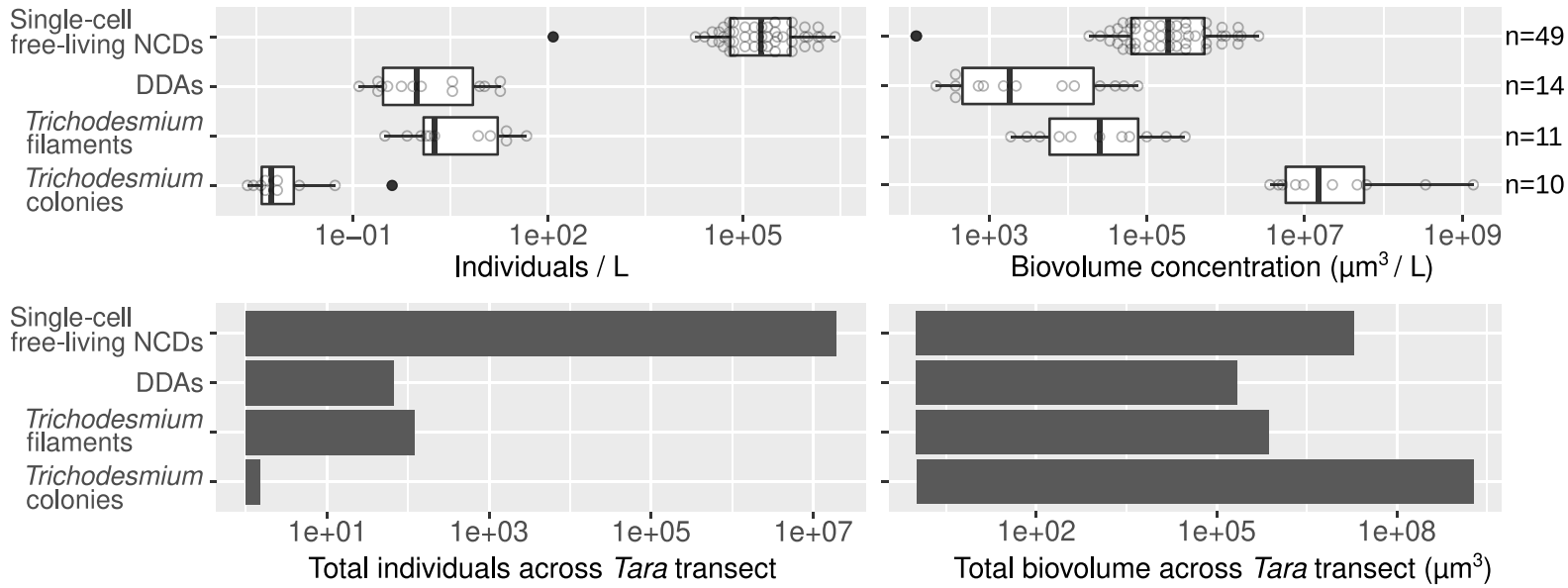

Total biovolume across Tara transect $\left(\mu \mathrm{m}^{3}\right)$

Fig. 3 Abundance and distribution of diazotrophs by quantitative imaging methods. a Biogeography in surface waters. Bubble size varies according to the corresponding diazotroph concentration (individuals/L), while red crosses indicate their absence. Station labels with detection of diazotrophs are indicated in blue. b Depth partition. Samples from the same geographical site are connected by red lines. c Distribution of individual abundances and biomass in surface waters. Single-cell free-living non-cyanobacterial diazotrophs (NCDs) were quantified by merging flow cytometry counts with nifH/recA ratio from metagenomes from size fraction $0.22-1.6 / 3 \mu \mathrm{m}$ and assuming an average cellular biovolume of $1 \mu \mathrm{m}^{3}$ based on the cell dimensions reported in the literature for cultured NCDs ${ }^{102-107}$. The detection and biovolume determinations of diatom-diazotroph associations (DDAs) and Trichodesmium-free filaments were carried out by high-throughput confocal microscopy in samples from the 20-180 $\mu \mathrm{m}$ size fraction. In the case of Trichodesmium colonies, it was determined using in situ images from the UVP5. Boxplots depict the 25-75\% quantile range of the dataset without zeros (the corresponding biologically independent seawater samples are indicated in the plot), with the center line depicting the median (50\% quantile); whiskers encompass data points within $1.5 \times$ the interquartile range. Source data are provided as a Source data file. 
Fig. S6), and confirms the tendencies observed in culture experiments ${ }^{42}$.

Single-cell free-living NCDs were estimated by combining flow cytometry estimates of free-living bacterial densities with diazotroph relative abundances derived from metagenomic sequencing of the $0.22-1.6 / 3 \mu \mathrm{m}$ plankton size fractions (see "Methods"). We

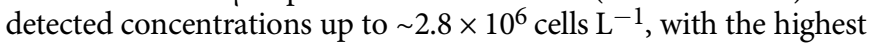
values in the Pacific Ocean (Fig. 3a). Our estimates agree with recent reports based on the reconstruction of metagenomeassembled genomes ${ }^{16}$.

Combining the imaging datasets from Tara Oceans (flow cytometry, confocal microscopy, and UVP5) enabled the conversion of abundances to estimates of biovolumes for the NCDs, Trichodesmium, and DDAs (Fig. 3c). Single-cell free-living NCDs are by far the most abundant diazotrophs in the surface ocean, however, Trichodesmium dominates in terms of biovolume by two orders of magnitude over NCDs (Fig. 3c). Cell density and biovolume of NCDs have not been previously reported at a global scale, thus the work presented here expands our understanding on the relative contributions for these recently recognized important diazotrophs.

Diazotroph diversity and abundance using metagenomes from size-fractionated plankton samples. To gain further insights into the abundance and distribution of diazotrophs across the whole plankton size spectrum, we compared the imaging data with metagenomic reads from the 5 main size fractions mapped against a comprehensive catalog of 29,609 unique nifH sequences (see "Methods"). The nifH catalog represents most of the genetic diversity reported for diazotroph isolates and environmental clone libraries (although it has some redundancy; see "Methods"), with $30 \%$ of the sequences derived from marine environments and the rest from terrestrial and freshwater habitats. Around $2.5 \%$ of these nifH sequences $(762$ out of 29,609$)$ mapped with at least $80 \%$ similarity to the 1164 metagenomes, retrieving a total of 96,215 mapped reads. Of the 762 sequences, 167 retrieved only one read. Mapped nifH reads were detected in slightly more than half of the samples (66\% or 771 of 1164 metagenomes), which highlights the broad distribution of diazotrophs in the Tara Oceans datasets (blue circles in Fig. 4a for surface waters; Supplementary Data 1).

The read abundance ratio of $n i f H / r e c A$ was used to estimate the relative contribution of diazotrophs (see "Methods"). Our analysis shows both a dramatic increase (up to 4 orders of magnitude) in diazotroph abundance and a compositional shift towards the larger size classes of plankton (Fig. 5). For example, diazotrophs comprise only a small proportion of the bacterial community in the $0.22-1.6 / 3 \mu \mathrm{m}$ size fraction $(0.004-0.8 \%)$, however, they increase to $0.003-40 \%$ in the $180-2000 \mu \mathrm{m}$ size range (Fig. 5a). The increase is coincident with a change in taxonomy (Fig. 5b, c, Supplementary Data 1): proteobacteria and planctomycetes are the main components in the $0.22-1.6 / 3 \mu \mathrm{m}$ size fraction (0.004-0.08\% and $0.005-0.4 \%$, respectively), while cyanobacterial diazotrophs dominate in the larger size fractions, including both filamentous (Trichodesmium and others) and non-filamentous types (free-living and symbiotic) $(0.2-45 \%$ and $0.2-2 \%$, respectively). A remarkable congruence was observed between the quantification based on imaging and metagenomic methods for the larger cyanobacterial diazotrophs (Fig. 6, Supplementary Figs. S3ab and S4ab). Hence, a fully reversible pipeline from images to genomics and genomics to images that allows each to inform the other was developed. The image analysis enables one to quickly identify which parallel metagenomic (or metatranscriptomic) sample(s) should contain a particular diazotroph. For populations like the cyanobacterial diazotrophs which are comparatively less abundant, this approach will reduce search time in genetic analyses.

The majority (95\%) of the total recruited reads mapping to the nifH database corresponded to 20 taxonomic groups: 5 cyanobacteria, 2 planctomycetes, and 13 proteobacteria. For the NCDs, the 2 planctomycetes and 7 of the 13 proteobacterial types corresponded to recent metagenome-assembled genomes (named HBD01 to HBD09 ${ }^{16}$ ) which additionally were among the top contributors to the nif $H$ transcript pool in the $0.22-1.6 / 3 \mu \mathrm{m}$ size fraction of Tara Oceans metatranscriptomes ${ }^{22}$. We also found these taxa in the larger size fractions (Figs. $5 \mathrm{c}$ and 7). The $0.8 \mu \mathrm{m}$ pore-size filter enriches for larger bacterial cells, while letting pass smaller diameter cells (including the more abundant taxa: SAR11 and Prochlorococcus). However, it is interesting that NCDs were detected in the three largest size fractions (5-20, 20-180, or 180-2000 $\mu \mathrm{m}$ ), suggesting NCDs attach to particles (e.g., marine snow, fecal pellets) ${ }^{43}$ and/or larger eukaryotic cells/organisms, aggregate into colonies ${ }^{44}$, or are possibly grazed by protists, suspension feeders and/or copepods 45 .

The main cyanobacterial taxa corresponded to Trichodesmium, Richelia/Calothrix, and UCYNs (UCYN-A1, UCYN-A2, and Crocosphaera). Trichodesmium represented the highest number of reads for nifH among all diazotrophs and constituted up to $40 \%$ of the bacterial community in the three largest size fractions (Figs. 5c and 7). Richelia nifH reads were also detected mainly in 5-20, 20-180, and 180-2000 $\mu \mathrm{m}$, while Calothrix was limited to $20-180 \mu \mathrm{m}$. Both observations are consistent with the expected association of Richelia/Calothrix with large and small diatoms (Hemiaulus, Rhizosolenia, Chaetoceros) (Figs. 1, 2, 5c, and 7), and the occasional report of free filaments. Free filaments were also detected in the confocal analyses (Supplementary Fig. S5; https:// www.ebi.ac.uk/biostudies/studies/S-BSST529). Relative abundance of UCYN-A1 was highest in the smaller size fractions $0.2-1.6 / 3 \mu \mathrm{m}$ and $0.8-5 \mu \mathrm{m}$, in accordance with the expected host cell size $(1-3 \mu \mathrm{m})^{11,46,47}$. However, UCYN-A1 was also detected in the larger size fractions $(5-20,20-180$, and $180-2000 \mu \mathrm{m})$ (Figs. 5c and 7) and suggests UCYN-A was grazed ${ }^{45}$ and/or associated with larger particles (e.g., marine snow or aggregates ${ }^{48}$ ), which may subsequently sink to the deep ocean (see next section). Crocosphaera was also found in multiple size fractions $(0.8-5,5-20,20-180$, and $180-2000 \mu \mathrm{m})$, which was expected given its diverse lifestyles: free-living, colonial, and symbiotic with large Climacodium diatoms (Fig. 1) ${ }^{12-14}$.

Unexpectedly, nifH sequences with high similarity to 'spheroid bodies' (Supplementary Fig. S7a) of a few freshwater rhopalodiacean diatoms ${ }^{49-51}$, were recruited in the surface waters of the 20-180 $\mu \mathrm{m}$ size fraction (Figs. $5 \mathrm{c}$ and 7 ). These observations were noted in multiple ocean basins (IO, SPO, and SAO; Supplementary Fig. S7b). Genome analysis of 'spheroid bodies' indicates the loss of photosynthesis ${ }^{52}$ and other metabolic pathways common to free-living cyanobacteria, and hence they are deemed obligate to their respective hosts. Therefore, we would not expect them in the smaller size fractions. To our knowledge, this is the first genetic evidence for the presence of these populations in marine waters. Detection levels were however low $(\sim 0.5 \%$ of the total bacterioplankton community) (Figs. $5 \mathrm{c}$ and 7 ), and consistent with the expected diatom host cell diameters $\left(\sim 30-40 \mu \mathrm{m}^{53}\right)$. Using published images of symbiotic rhopalodiacean diatoms ${ }^{54}$, we manually selected similar images in the samples of interest and used them as a training set. The image recognition model predicted several images of pennate diatoms containing round granules without chlorophyll autofluorescence (Supplementary Fig. S7c). However, our predictions are preliminary, and require further validation by other methods that are outside the scope of this work to verify whether they are indeed diazotrophic symbionts. 

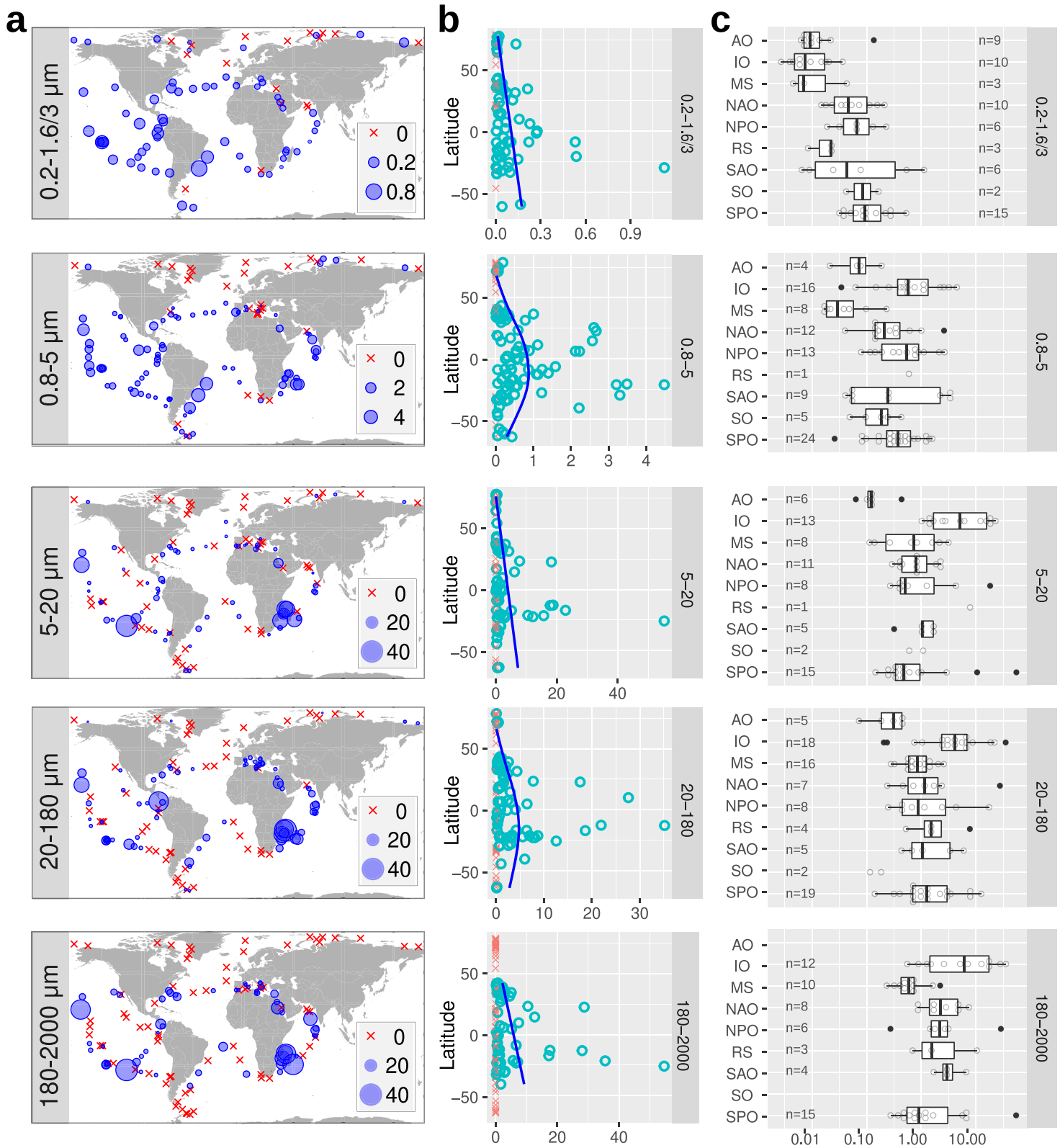

$\%$ diazotrophs among bacterioplankton ( $\mathrm{nifH} / \mathrm{rec}$ * $100 \%)$

Fig. 4 Biogeography of diazotrophs in surface waters using metagenomes obtained from different size-fractionated samples. The percentage of diazotrophs in the bacterioplankton community was estimated by the ratio of metagenomic read abundance between the marker genes nifH and recA. a Biogeography. The bubble size varies according to the percentage of diazotrophs, while red crosses indicate absence (i.e., no detection of nifH reads). b Latitudinal abundance gradient. The blue lines correspond to generalized additive model smoothings. c Ocean distribution. MS Mediterranean Sea, IO Indian Ocean, SAO South Atlantic Ocean, SO Southern Ocean, SPO South Pacific Ocean, NPO North Pacific Ocean, NAO North Atlantic Ocean, AO Arctic Ocean. Boxplots depict the $25-75 \%$ quantile range of the dataset without zeros (the corresponding biologically independent seawater samples are indicated in the plot), with the center line depicting the median ( $50 \%$ quantile); whiskers encompass data points within $1.5 \times$ the interquartile range. Source data are provided as a Source data file.

Evidence of polyploidy. To date, polyploidy has been reported in NCDs of soil 55,56 , in some heterocystous and UCYN cyanobacteria $^{56-59}$, and in a field/cultured study of Trichodesmium ${ }^{60}$. It, however, remains unknown in marine NCDs, diazotrophic UCYNs, and Richelia/Calothrix populations. Hence we cannot discount that the nifH abundances for the diazotrophs was not influenced by ploidy. Here we have attempted to estimate whether ploidy influences Trichodesmium and Richelia/Calothrix abundances since we have quantifications for both based on imaging and genetic methods from the same samples (Fig. 6). However, it is important to note that the metagenomic sampling from Tara Oceans was not specifically designed to quantify metagenomic signals per seawater volume due to the lack of 'spike-ins' or DNA internal standards, and thus we have made assumptions in order to approximate estimates using the reported sampled seawater volumes and the quantity of extracted DNA (see "Methods"). Based on these assumptions, our results show the polyploidy for Trichodesmium is 5 (median of 15 points) and 2 for Richelia/Calothrix (median of 21 points), but both taxa show variability of polyploidy values according to the sample (range of 0.3-58; Supplementary Data 2). These results are within the range of polyploidy reported previously for field 
a

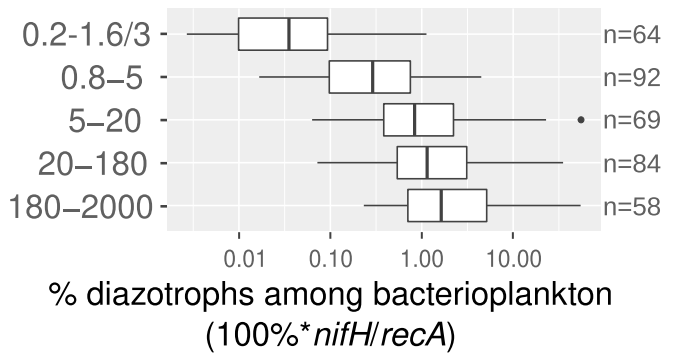

b

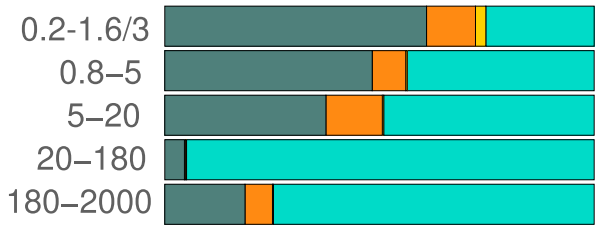

Taxonomic distribution of $\mathrm{nifH}$ reads

Cyanobacteria

Other/Unassigned
Planctomycetes
Proteobacteria
C

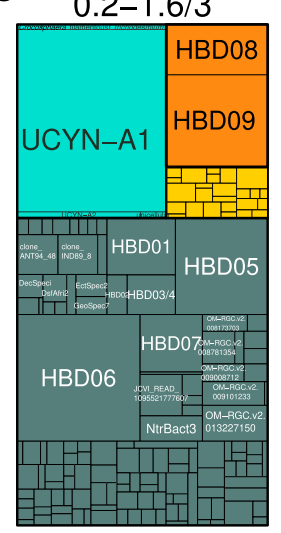

$0.8-5$

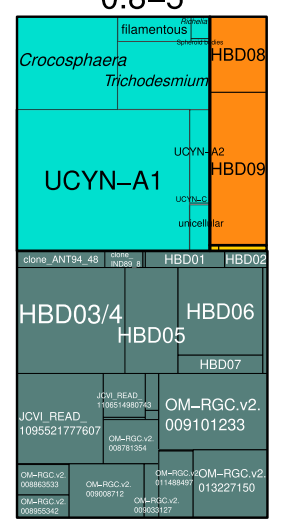

$5-20$

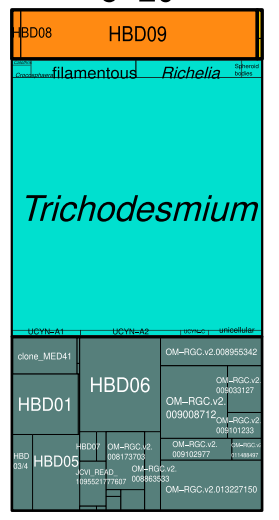

$20-180$

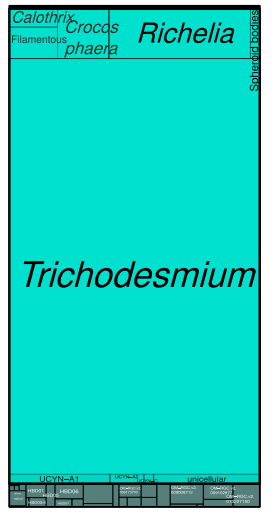

180-2000

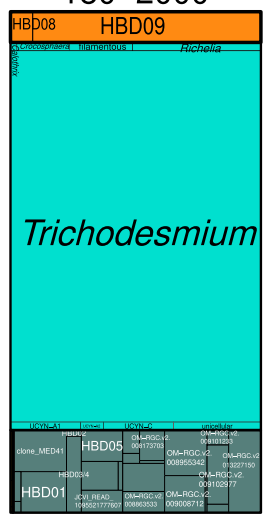

Fig. 5 Abundance of diazotrophs in surface waters using metagenomes obtained from different size-fractionated samples. a Diazotroph abundance. The percentage of diazotrophs in the bacterioplankton community was estimated by the ratio of metagenomic read abundance between the marker genes nifH and recA. b Taxonomic distribution of the nifH reads. c Taxonomic distribution at deeper resolution. HBD01 to HBD09 (heterotrophic bacterial diazotrophs) corresponds to the metagenome-assembled genomes from $<3-\mu \mathrm{m}$ size fractions ${ }^{16}$. Boxplots depict the $25-75 \%$ quantile range of the dataset without zeros (the corresponding biologically independent seawater samples are indicated in the plot), with the center line depicting the median ( $50 \%$ quantile); whiskers encompass data points within $1.5 \times$ the interquartile range. Source data are provided as a Source data file.

populations of Trichodesmium (range of 1-120; ref. ${ }^{60}$ ), but below those observed in culture conditions (range 639-697; ref. ${ }^{60}$ ). When comparing the polyploidy of Trichodesmium vs Richelia/Calothrix in the 12 samples in which both are detected, the estimate for Trichodesmium is on average 4 times the estimate for Richelia/Calothrix (range 0.1-15) (Supplementary Data 2). Therefore, Trichodesmium dominance over Richelia/Calothrix is overestimated in the metagenomes due to the higher polyploidy levels of the former. Equivalent values for NCDs and UCYNs will be needed to evaluate the effect of polyploidy in the whole diazotroph community. In addition, it is important to note in previous works suggest that the degree of ploidy depends on the growth conditions, nutrient status, developmental stage, and cell cycle $^{55-60}$.

Insights into environmental distribution and depth partitioning of diazotrophs. Diazotroph abundance was latitudinally influenced and shows expected higher relative abundances in tropical and subtropical regions, and a decrease at the equator where upwelling and higher dissolved nutrients are expected (Fig. 4). This pattern is congruent with decades of field observations (e.g., NAO, NPO) as well as modeling efforts ${ }^{20,61,62}$, and the correlation analyses of environmental and physico-chemical variables measured during Tara Oceans (Fig. 8). Temperature and nutrient availability are common factors which govern diazotroph abundances $8,20,63$. Iron is also expected to be important due to the high iron requirement of the nitrogenase enzyme ${ }^{64,65}$, therefore it was unexpected to find a less robust relationship between diazotroph abundances and modeled dissolved iron concentrations (Fig. 8a). However, we cannot discount inaccuracies of modeled values relative to in situ bioavailable Fe concentrations.

We further analyzed abundance and distribution patterns in the deeper depth samples $(0-200 \mathrm{~m}$ and $200-1000 \mathrm{~m}$, respectively). The higher numbers of $\mathrm{N}_{2}$-fixing cyanobacteria detected in the surface $(5 \mathrm{~m})$ compared to the deep chlorophyll maximum (DCM; 17-188 m) in both the metagenomic and imaging datasets confirms expected distributions (Figs. $3 \mathrm{~b}$ and $8 \mathrm{c}$, also compare Fig. 9 and Supplementary Fig. S8). However, detection of both Trichodesmium and the DDA symbionts were nonetheless significant in some DCM samples from diverse regions: IO, SPO, and Red Sea (RS) (Supplementary Fig. S8). DDAs are expected at depth given the reported rapid sinking rates, and observations in moored sediment traps (station ALOHA: refs. ${ }^{39,40,66}$ ). Traditionally Trichodesmium has been considered to have a poor export capacity ${ }^{67}$, however, recently there are contrary reports, and therefore Trichodesmium is also expected at depth $40,68,69$. Increased abundances of Crocosphaera co-occurred in the DCM of IO samples in the larger $(5-20 \mu \mathrm{m})$ size fraction; indicative of the colonial and/or symbiotic lifestyles previously reported for Crocosphaera (Fig. 1; refs. 12,70). Unlike the phototrophic diazotrophs, the distribution of NCDs had no apparent depth partitioning in the epipelagic layer (Fig. 8c).

A relatively high number of nifH reads was detected in mesopelagic samples (110 out of 128 -or $86 \%$ - of mesopelagic samples, Supplementary Fig. S9). Although BNF and nifH expression has been previously reported at depth, most measurements have been made in oxygen minimum zones (OMZs; where low-oxygen waters are found) and oxygen-deficient zones (ODZs; where oxygen concentrations are low enough to induce anaerobic metabolisms) ${ }^{17,22}$. Here, nifH sequences mapped from many 

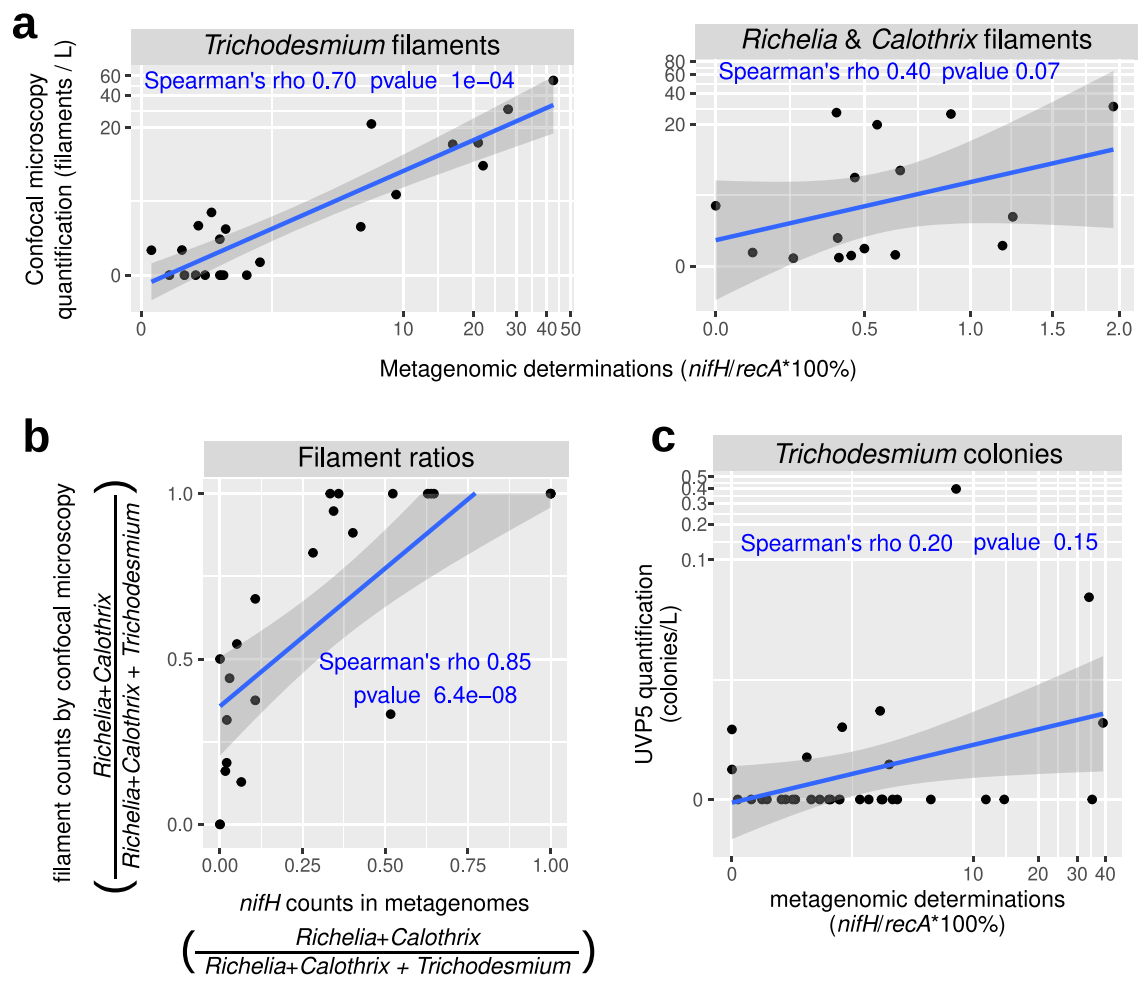

Fig. 6 Correlation analysis between diazotroph quantifications by imaging and molecular methods. a, $\mathbf{b}$ Comparison between environmental high content fluorescence microscopy (eHCFM ${ }^{30}$ ) and metagenomics. Calothrix, Richelia, and Trichodesmium in samples from size fraction $20-180 \mu \mathrm{m}$ were measured by quantification of high-throughput confocal microscopy images (filaments $\mathrm{L}^{-1}$ ) and by metagenomic counts (\% of diazotrophs in the bacterioplankton community by the ratio between the marker genes nifH and recA). a Correlation of relative abundances in metagenomes and absolute abundances by confocal microscopy for the three taxa. b Correlation between the ratio of abundances between taxa. c Comparison between Underwater Vision Profiler 5 (UVP5 ${ }^{33}$ ) and metagenomics. Trichodesmium colonies were measured by UVP5 quantification (colonies $L^{-1}$ ) and by metagenomic counts in the 180-2000 $\mu \mathrm{m}$ size-fractionated samples. Spearman's rho correlation coefficients and uncorrected one-side p-values are displayed in blue. Source data are provided as a Source data file.

mesopelagic samples outside of OMZs and ODZs including in SPO, NPO, NAO, and SAO (Supplementary Fig. S9). The majority of nifH sequences correspond to proteobacteria, however, diazotrophic cyanobacteria were also detected (Supplementary Fig. S9). In particular, $44 \%$ of total nifH reads in mesopelagic samples at TARA_78 and 6\% at TARA_76 (of 0.2-3 $\mu \mathrm{m}$ size fraction) in SAO corresponded exclusively to UCYN-A (Supplementary Fig. S9, Supplementary Data 1). The maximum numbers of UCYN-A reads in all Tara Oceans samples were detected in the corresponding surface samples at these stations (Fig. 9; see below), suggesting a surface bloom. Most reports indicate the presence and activity of UCYN-A in the sunlit zone, with the exception of a study reporting UCYN-A nifH sequences in shallow water sediments of the north east Atlantic ocean (seafloor 38-76-m depth) ${ }^{71}$. Our observation of UCYN-A at 800$\mathrm{m}$ depth in the open ocean suggests that this symbiosis could contribute to carbon export despite its small cell diameter, or that other physical processes (e.g., subduction, downwelling, upwelling) in this ocean region were influencing the high detection of UCYN-A at depth.

Global ocean biogeography of diazotrophs. Several regions displayed high densities or "hotspots" of diazotrophs which have not been previously sampled (Figs. 4 and 9, Supplementary Fig. S10). For example, in the Mozambique Channel between Madagascar and the African continent, diazotrophs constituted up to $30-40 \%$ of the bacterioplankton in the larger size fraction samples (TARA_50 to TARA_62; Figs. 4 and 9). The latter molecular results were confirmed by images of both Trichodesmium and symbiotic diazotrophs (Fig. 3a). Another example is the SAO near South America (TARA_76, TARA_78, and TARA_80), where UCYN-A reached 3-4\% of the bacterioplankton population in the $0.8-5 \mu \mathrm{m}$ size fraction (Figs. 4 and 9). These zones from IO and SAO represent previously undersampled regions for diazotrophs (Supplementary Fig. S1), which also lack quantitative rate measurements for $\mathrm{BNF}^{19}$.

The highest abundance of free-living single-cell NCDs $(0.2-3$ $\mu \mathrm{m})$ corresponded to $\sim 0.5 \%$ of the bacterioplankton in the wake of the Marquesas archipelago in the equatorial PO (TARA_123; Fig. 9). This station was reported recently as a surface planktonic bloom triggered by natural iron fertilization ${ }^{72}$. Other high-density areas corresponded to a few stations in the SPO (surface samples of TARA_98 and TARA_99 and DCM of TARA_102), where high abundances of proteobacteria and planctomycetes (4-33\% and $8-9 \%$, respectively) were found in larger size fractions (Fig. 9 and Supplementary Fig. S8), which likely results from association of NCDs to sinking particles. Moreover, TARA_102 is located in the Peruvian upwelling area, a region previously reported for NCDs and/or BNF activity associated with the OMZ ${ }^{73-75}$. These results are congruent with recent reports from the subtropical Pacific of highly diverse NCDs, some associated with sinking particles ${ }^{18,75-77}$. We can therefore expand the distribution of potentially particle-associated NCDs to several other ocean basins (NAO, AO, IO). Our findings emphasize the dominance and persistence of NCDs in larger size fractions of both surface and DCM, which is new information to our knowledge and warrants further investigation. 


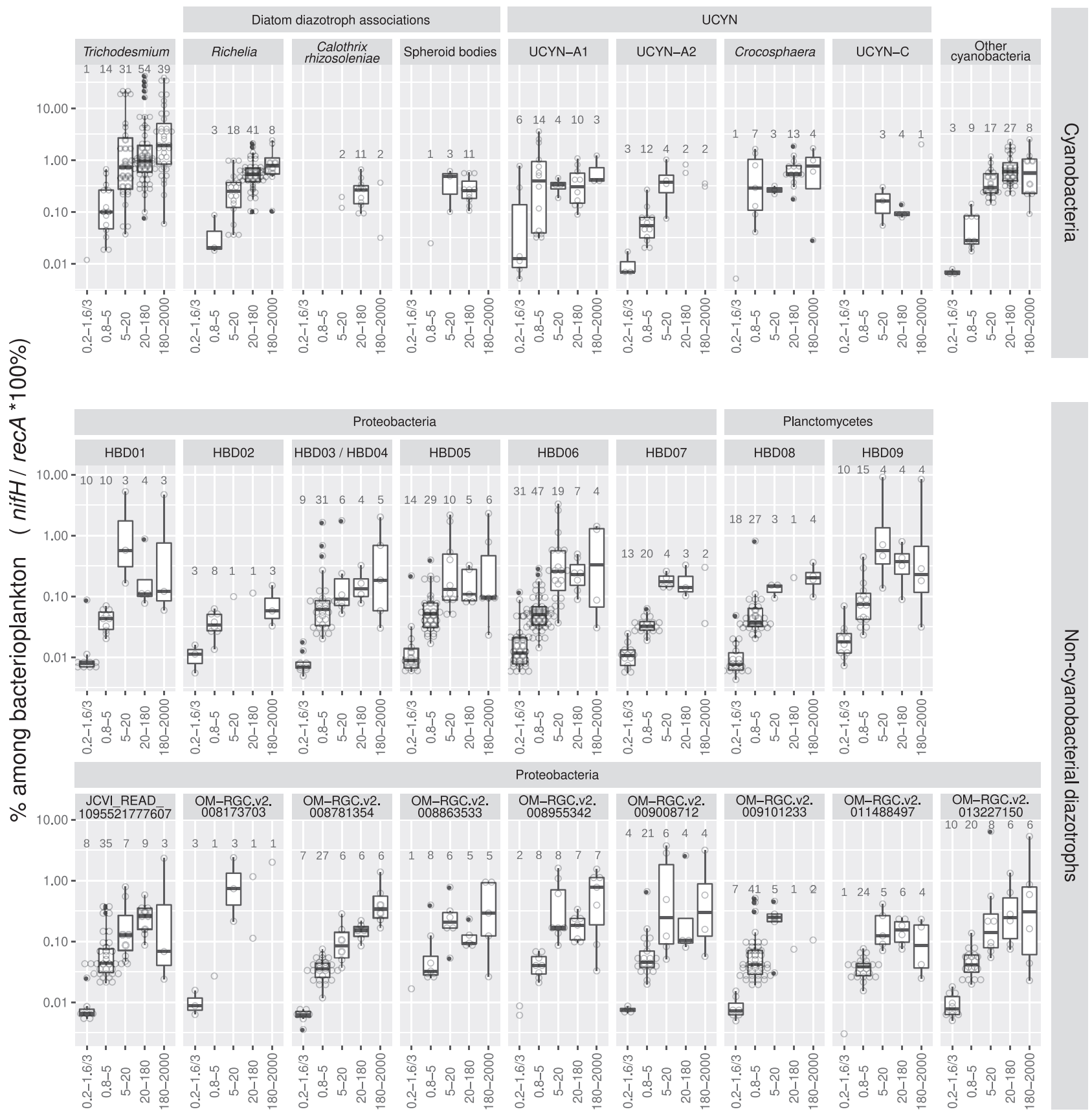

Fig. 7 Distribution of the main diazotroph taxa across metagenomes obtained in different size-fractionated samples from surface waters. For each taxon, the percentage in the bacterioplankton community is estimated by the ratio of metagenomic read abundance between the marker genes nifH and recA. The lineages grouped into 'Other cyanobacteria' are displayed in the Source data File. The 'OM-RGC.v2' prefix indicates the nifH sequences assembled from the metagenomes of $<3-\mu$ m size fractions 22 , while HBD01 to HBD09 (heterotrophic bacterial diazotrophs) corresponds to the metagenome-assembled genomes from the same samples ${ }^{16}$. Boxplots depict the $25-75 \%$ quantile range of the dataset without zeros (the corresponding biologically independent seawater samples are indicated in the plot), with the center line depicting the median (50\% quantile); whiskers encompass data points within $1.5 \times$ the interquartile range. Source data are provided as a Source data file.

Many regions contain a low abundance of diazotrophs. For example, the percentages of diazotrophs in the AO, the Southern Ocean (SO), and the Mediterranean Sea (MS) reached maximum values of only $0.4,1$, and $4 \%$, respectively (Figs. $4 \mathrm{c}$ and 9). The highest diazotroph abundance in the $\mathrm{AO}$ corresponded to NCDs found in shallow waters $(20-25 \mathrm{~m}$ depth) of the East Siberian Sea (TARA_191; Figs. 4c and 9), a biologically undersampled region. Combined, the results concerning distribution reported here emphasize the patchy biogeographical patterns of diazotrophs.
Cyanobacterial diazotrophs are mainly found as assemblies of abundant groups. With the exception of a few stations in IO, RS, NPO, and NAO where Trichodesmium was the main component of the mapped reads (Figs. $8 \mathrm{~b}$ and 9, Supplementary Fig. S11), there was a general and consistent trend of cooccurrence for several cyanobacterial diazotrophs in multiple oceanic regions (Fig. 9 and Supplementary Fig. S11). For example, in the Red Sea (RS), southern IO, and at station ALOHA, both larger (Trichodesmium, Richelia) and smaller (UCYN-A, Crocosphaera) diameter diazotrophs were 
a

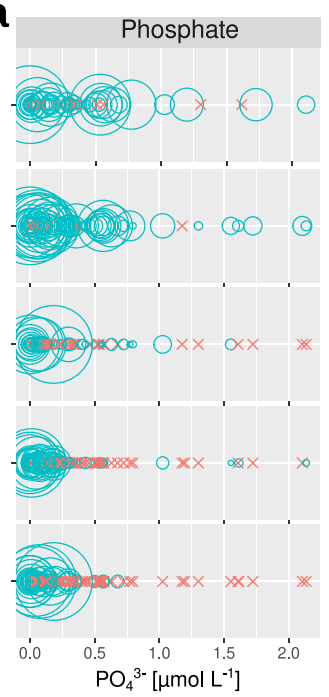

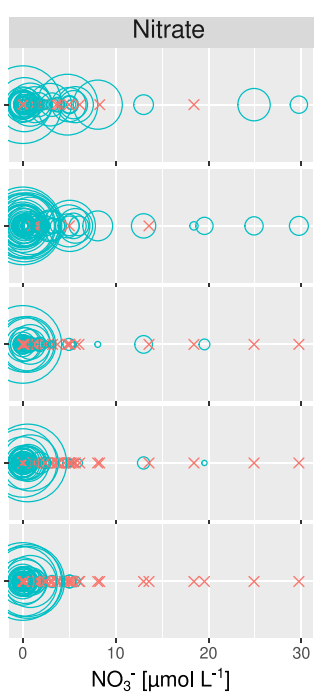

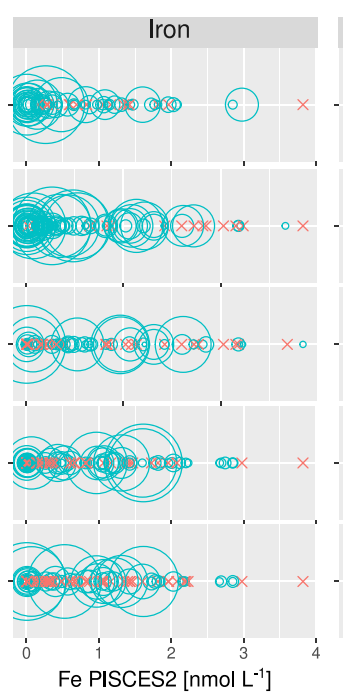

Fe PISCES2 [nmol L-1]

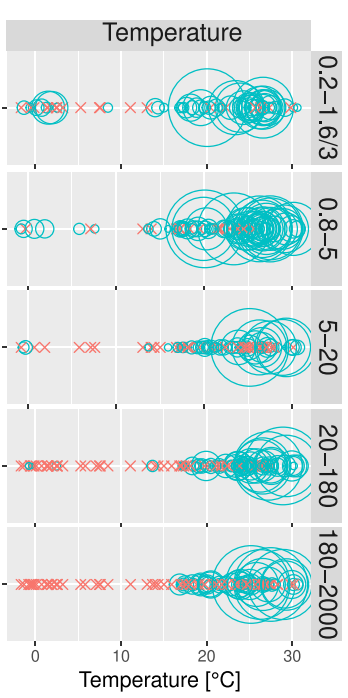

$\%$ diazotrophs (nifH / recA $\times 100 \%)$
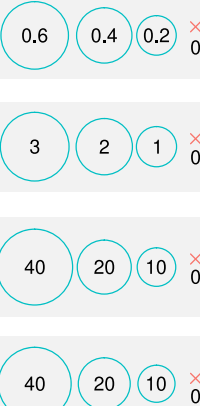

$4020 \times$ b
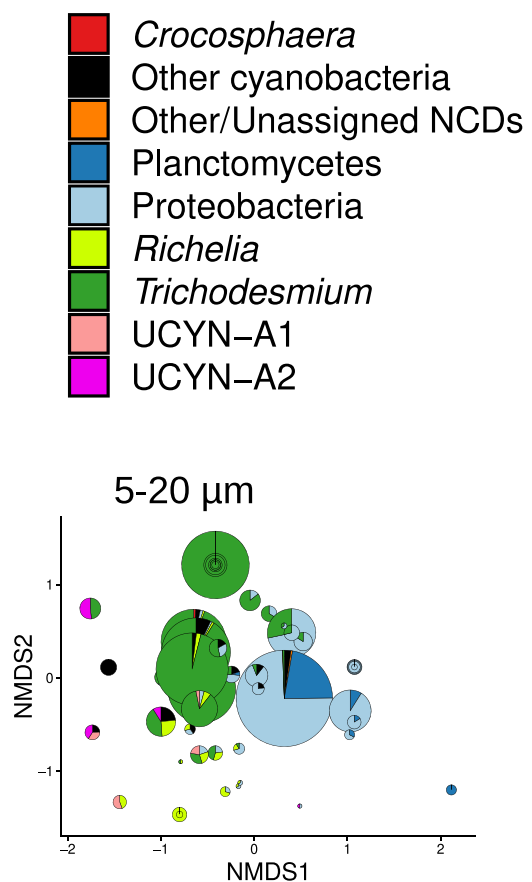
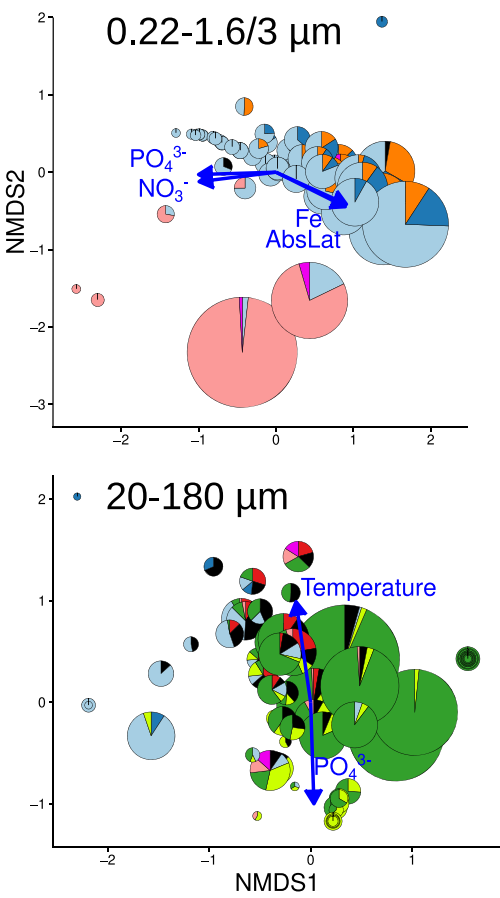
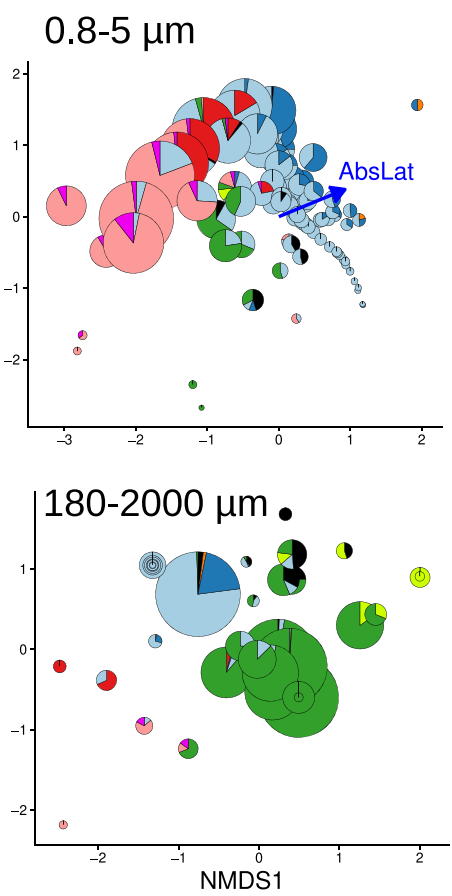

C

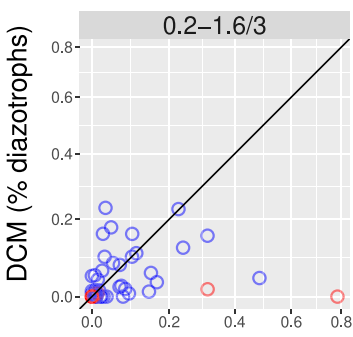

- Non-cyanobacterial diazotrophs

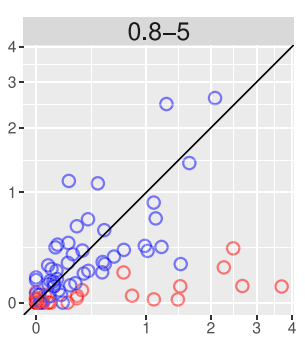

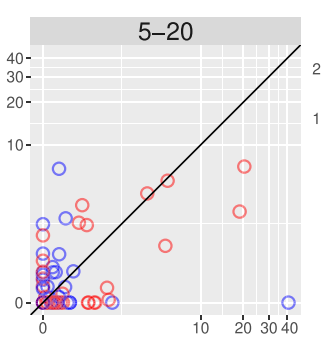

Surface (\% diazotrophs) $\circ$ Cyanobacteria
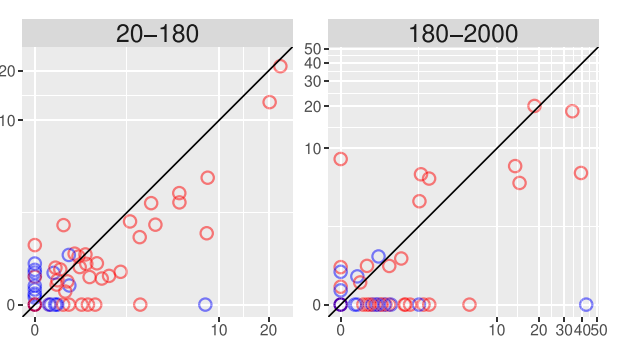

Fig. 8 Environmental parameters and diazotroph distributions. a Distribution across gradients of nutrients and temperature in surface waters. Blue circles correspond to samples with diazotrophs, while red crosses indicate absence (i.e., no detection of nifH reads). $\mathbf{b}$ NMDS analysis of stations according to Bray-Curtis distance between diazotroph communities of size-fractionated surface samples. Fitted statistically significant physico-chemical parameters are displayed (adjusted $P$ value $<0.05$ ). NMDS stress values: $0.07276045,0.1122258,0.1452893,0.09693721$, and 0.07969211 . c Depth distribution. The scatter plots compare the diazotroph abundances between surface $(5 \mathrm{~m})$ and deep chlorophyll maximum (DCM; 17-180 m) for cyanobacteria (red points) and non-cyanobacterial diazotrophs (NCDs, blue points). Axes are in the same scale and the diagonal line corresponds to a 1:1 slope. Source data are provided as a Source data file. 


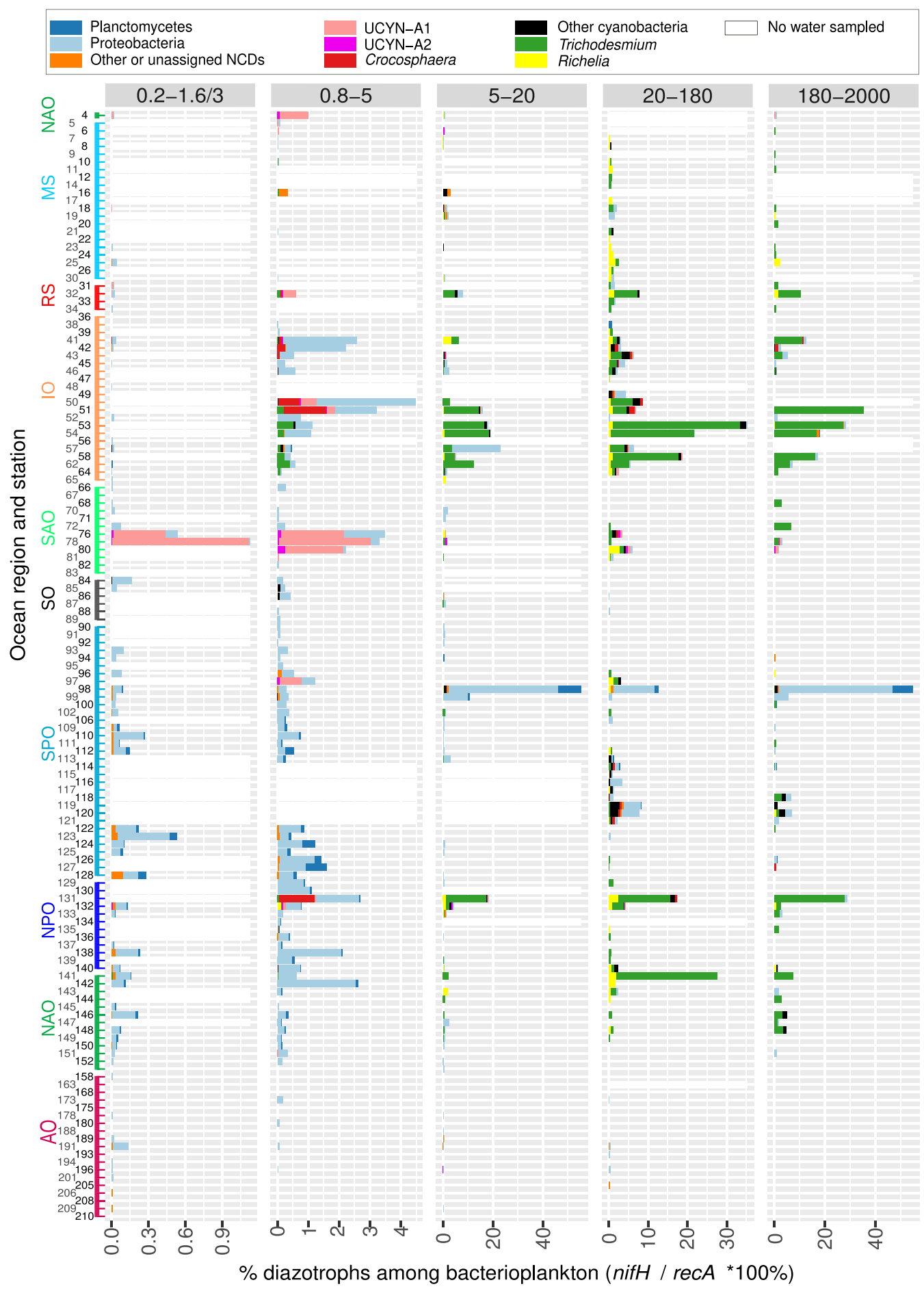

Fig. 9 Diazotroph community based on metagenomes from size-fractionated surface samples. The percentage of diazotrophs in the bacterioplankton community was estimated by the ratio of metagenomic read abundance between the marker genes nifH and recA. The bar color code shows the taxonomic annotation, while the absence of water sample is indicated by a white bar. The Y-axis shows the Tara Oceans stations and the ocean regions. MS Mediterranean Sea, IO Indian Ocean, SAO South Atlantic Ocean, SO Southern Ocean, SPO South Pacific Ocean, NPO North Pacific Ocean, NAO North Atlantic Ocean, AO Arctic Ocean. The equivalent figure showing the DCM water layer is shown in Fig. S2 (note the differences in scales between both figures, showing the higher relative abundance of diazotrophs in the surface layer). Source data are provided as a Source data file.

detected (Fig. 9 and Supplementary Fig. S11). In fact, UCYN-A has yet to be reported in the RS, while all other cyanobacterial diazotrophs have been reported previously, including surface blooms of Trichodesmium spp. ${ }^{78-81}$. On the contrary, only small diameter diazotrophs co-dominated in the SAO; for example, UCYN-A1 and UCYN-A2 were very abundant at stations TARA_76, TARA_78, and TARA_80 (Fig. 9 and Supplementary Fig. S11). The numerous and consistent observations of mixed diazotrophic assemblages of different sizes and lifestyles (colonial, free-living, symbiotic, particleassociated) highlight the need to consider how these traits enable co-occurrence. 
Ultrasmall diazotrophs consist of proteobacteria and are abundant in the Arctic Ocean. Ultrasmall prokaryotes are unusual due to their reduced cell volume (these cells can pass through $0.22-\mu \mathrm{m}$ filters, a size usually expected to exclude most microorganisms), and thus they are thought to have reduced genomes and to lack the proteins needed to carry out more complex metabolic processes. However, there is recent evidence that they do indeed participate in complex metabolisms ${ }^{82}$. To examine whether they may also contribute to marine BNF, we carried out the analysis of 127 metagenomes of $<0.22 \mu \mathrm{m}$ sizefractionated samples from different water layers.

A total of 79 nifH sequences in our database mapped with at least $80 \%$ similarity to these metagenomes, retrieving a total of 43,161 mapped reads, with the majority of the reads having high identity to proteobacterial nifH sequences. Of the 79 sequences, 15 retrieved only one read. Mapped nifH reads were detected in 92 of the 127 samples (72\%), which highlights an unexpected broad distribution of ultrasmall diazotrophs (blue circles in Fig. 10a; Supplementary Data 1). Notably, when nifH reads were normalized by recA reads, we found that diazotrophs comprise up to $10 \%$ of the ultrasmall bacterioplankton, with the highest abundances detected in the $\mathrm{AO}$, and in different water layers (Fig. 10a, b). This is remarkable considering that the lowest diazotroph abundance in the other size fractions was detected in the AO (Figs. 4c and 9, Supplementary Figs. S8 and S9).

The majority (84\%) of the total recruited reads mapping to the nif $H$ database corresponded to two sequences assembled from the $<0.22 \mu \mathrm{m}$ size-fractionated metagenomes: OM-RGC. v2.008173703 and OM-RGC.v2.008955342. The former has 99\% identity to nifH from the epsilon-proteobacterium Arcobacter nitrofigilis DSM729983 (hereafter Arcobacter), the second is more close in sequence identity to gamma-proteobacteria. The Acrobacter-like sequence only retrieved reads from surface and DCM, while the gamma-proteobacterium-like retrieved reads from surface, DCM, and mesopelagic (Fig. 10c). Both sequences also retrieved reads from other sizes fractions (Fig. 7 and Supplementary Fig. S12). Members of Arcobacter genus are either symbionts or pathogens ${ }^{83}$, which is inconsistent with $>9 \%$ of ultrasmall bacterioplankton associated with the $<0.22 \mu \mathrm{m}$ size fraction in the DCM waters of station TARA_158 (Supplementary Fig. S12). An additional proteobacterial sequence (OM-RGC. v2.008817394) almost exclusively retrieved reads from the $<0.22$ $\mu \mathrm{m}$ size-fractionated samples (Supplementary Fig. S12). Combined, these results prompt the inclusion of ultrasmall diazotrophs in future field surveys to quantify their potential ecological and biogeochemical importance.
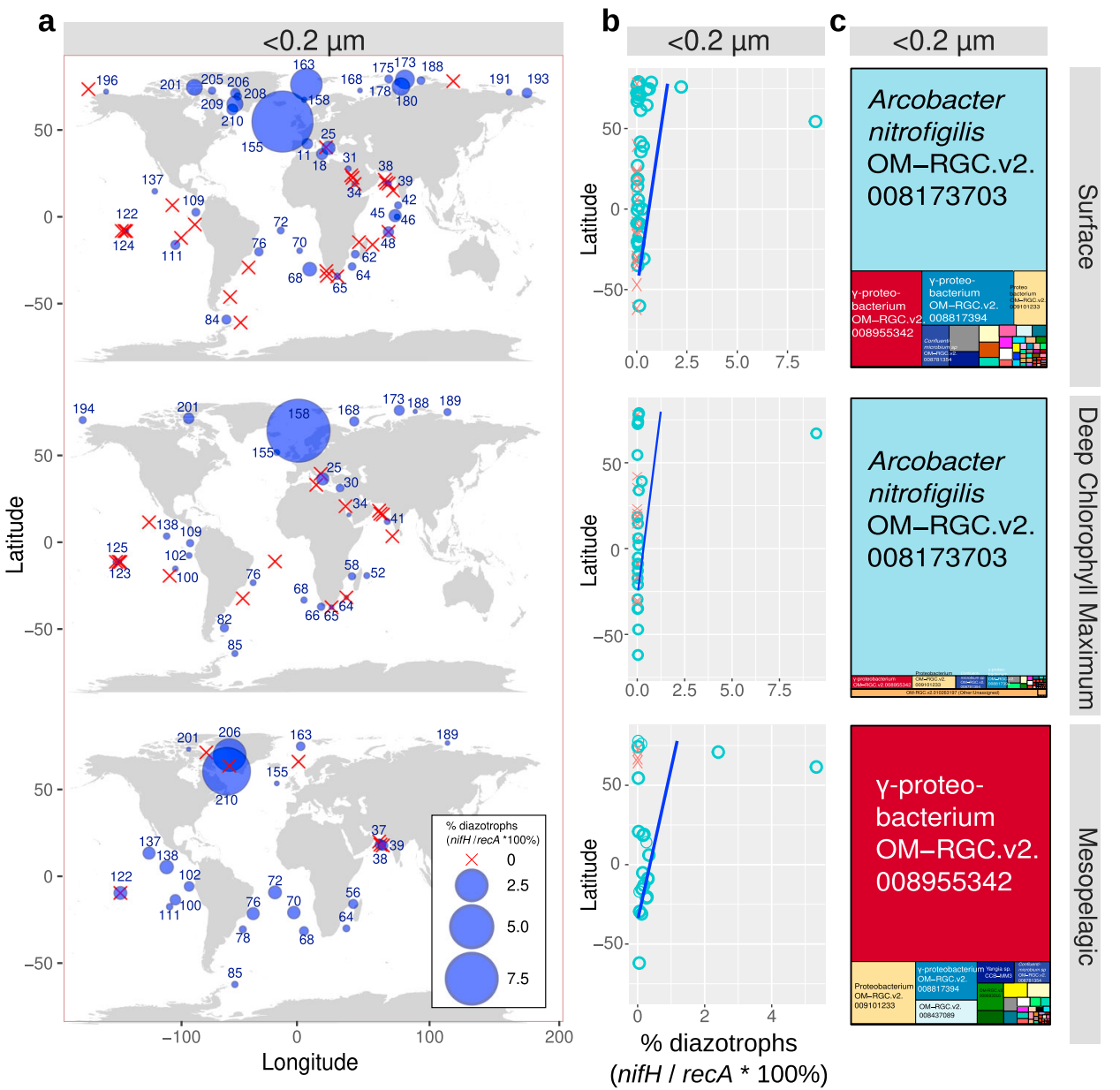

Fig. 10 Detection of ultrasmall diazotrophs in metagenomes obtained from $<0.22 \boldsymbol{\mu m}$ size-fractionated samples of different water layers. The percentage of diazotrophs among ultrasmall bacterioplankton was estimated by the ratio of metagenomic read abundance between the marker genes nifH and recA. a Biogeography. The bubble size varies according to the percentage of diazotrophs, while red crosses indicate absence (i.e., no detection of nifH reads). Station labels with diazotrophs detection are indicated in blue. $\mathbf{b}$ Latitudinal abundance gradient. Circles correspond to samples with diazotrophs, while crosses indicate absence. The blue lines correspond to generalized additive model smoothings. $\mathbf{c}$ Taxonomic distribution of the nifH reads. The 'OMRGC.v2' prefix indicates the nifH sequences assembled from metagenomes of $<3 \mu \mathrm{m}$ size fractions ${ }^{22}$, including $<0.22 \mu \mathrm{m}$. Source data are provided as a Source data file. 
In conclusion, the present work represents the first attempt, to our knowledge, to assess the diversity, abundance, distribution, and biovolume of diazotrophs at a global ocean scale using paired image and PCR-free molecular analyses. Unlike earlier studies, our work included the full biological and ecological complexity of diazotrophs: i.e., unicellular, colonial, particle-associated, symbiotic, cyanobacteria, and NCDs. Diazotrophs were found to be globally distributed and present in all size fractions, even among ultrasmall bacterioplankton $(<0.22 \mu \mathrm{m})$, which were especially abundant in the AO. Unexpectedly, we detected sequences similar to obligate symbionts of freshwater diatoms nearly exclusively in the larger size fraction, in multiple and geographically distinct regions of the world's ocean. A major conclusion from our work is the identification of new hotspots for diazotrophs in previously undersampled regions. Historically and recently, the field has attempted to make paradigm shifts in favor of one dominant group (large vs. small diameter cyanobacterial diazotrophs). The data presented here on the contrary argues in favor of regions of co-existing assemblages of cyanobacterial diazotrophs with diverse lifestyles (colonial, free-living, symbiotic, particle-associated), while NCDs appear ubiquitously distributed. Overall, this work provides an updated composite of diazotroph biogeography in the global ocean, providing valuable information in the context of global change and the substantial anthropogenic perturbations to the marine nitrogen cycle.

\section{Methods}

Tara Oceans sampling. Tara Oceans performed a worldwide sampling of plankton between 2009 and 2013 (Supplementary Fig. S1b). Three different water depths were sampled: surface (5-m depth), DCM (17-188 m), and mesopelagic (200-1000 m) (Supplementary Fig. S2). The plankton were separated into discrete size fractions using a serial filtration system ${ }^{21}$. Given the inverse logarithmic relationship between plankton size and abundance ${ }^{21,84}$, higher seawater volumes were filtered for the larger size fractions $\left(10-10^{5} \mathrm{~L}\right.$; see Table 1 and Fig. 5 in ref. $\left.{ }^{21}\right)$. Taking into account that diazotrophs are less abundant than sympatric populations and have a wide size variation (Fig. 1), a comprehensive perspective requires analyses over a broad spectrum, which to date has been lacking. Five major organismal size fractions were collected: picoplankton $(0.2-1.6 \mu \mathrm{m}$ or $0.2-3 \mu \mathrm{m}$; named here $0.2-1.6 / 3 \mu \mathrm{m}$ size fraction), piconanoplankton $(0.8-5 \mu \mathrm{m}$ or $0.8-2000$ $\mu \mathrm{m}$; named here $0.8-5 \mu \mathrm{m}$ size fraction), nanoplankton $(5-20 \mu \mathrm{m}$ or $3-20 \mu \mathrm{m}$; named here 5-20 $\mu \mathrm{m}$ size fraction), microplankton $(20-180 \mu \mathrm{m})$, and mesoplankton $(180-2000 \mu \mathrm{m})$ (Supplementary Fig. S2) ${ }^{21}$. In addition, ultrasmall plankton $(<0.22 \mu \mathrm{m})$ were also collected (Supplementary Fig. S2) ${ }^{21}$. The Tara Oceans datasets used in the present work are listed in Supplementary Fig. S2 and specific details about them and their analyses are described below.

Read recruitment of marker genes in metagenomes. The use of metagenomes avoids the biases linked to the PCR amplification steps of metabarcoding methods, and thus it is better for quantitative observations. This is especially important for protein-coding gene markers, such as $n i f H$, which display high variability in the third position of most codons, and thus necessitate the use of highly degenerate primers for a broad taxonomic coverage ${ }^{85}$. The detection of low-abundance organisms, such as diazotrophs, is facilitated by the deep sequencing of the Tara Oceans samples (between $\sim 10^{8}$ and $\sim 10^{9}$ total metagenomic reads per sample $)^{22,24,25}$. The 1326 metagenomes generated by the expedition are derived from 147 globally distributed stations and three different water layers: 745 metagenomes from surface, 382 from DCM (17-188 m), and 41 from the bottom of the mixed layer when no DCM was observed (25-140 m), and 158 from mesopelagic (200-1000 m) (Supplementary Fig. S2).

The read abundance of the single-copy gene $\operatorname{rec} A$ was used to estimate the total bacterial community abundance in each sample (in contrast to the widely used $16 \mathrm{~S}$ rRNA gene, which varies between 1 and 15 copies among bacterial genomes ${ }^{86,87}$ ). For simplicity, we assumed that nifH is also a single-copy gene, so the abundance ratio of $n i f H / r e c A$ provides an estimate for the relative contribution of diazotrophs to the total bacterial community. However, we realize that there are examples of 2-3 nifH copies in heterocyst-forming cyanobacteria such as Anabaena variabilis and Fischerella sp. ${ }^{88,89}$, or in the firmicutes Clostridium pasteurianum ${ }^{90}$, and that we are not taking into account the polyploidy effect.

The metagenomes were aligned against sequence catalogs of marker genes for diazotrophs (nifH) and bacteria ( $\operatorname{rec} A)$ (Supplementary Data 3 and 4$)$. The analysis was carried out using bwa tool version $0.7 .4^{91}$ using the following parameters: -minReadSize 70 -identity 80 -alignment 80 -complexityPercent 75 -complexityNumber 30 . The nifH sequence catalog (hereafter nifH database) was composed of 29,175 publicly available unique sequences from the laboratory of JP
Zehr (University of California, Santa Cruz, USA; version April 2014; https://www. jzehrlab.com). Although the Zehr database has some redundancy (9048 out of the 29,175 total unique sequences are retained when clustered at $95 \%$ identity using CDHIT-EST tool ${ }^{92}$ ), all non-identical sequences were used to maximize the number of metagenomic mapping reads. Moreover, this database was complemented with additional nifH genes retrieved from the sequenced genomes of Integrated Microbial Genome database (IMG) ${ }^{93}$ and from different Tara Oceans datasets: Ocean Microbial Reference Gene Catalog version 2 (OM-RGC-v2 ${ }^{22}$ ), assemblies $^{16}$ and 10 clones (this study). nifH clone libraries were built using DNA extracted from 0.2 to $1.6 / 3 \mu \mathrm{m}$ size fraction plankton samples as described in Alberti et al. ${ }^{24}$. DNA samples from the same oceanic region were pooled together at a concentration of $10 \mathrm{ng} / \mu \mathrm{l}$ and used as template in a nested nifH PCR using degenerate primers (Supplementary Data $3^{94}$ ). Five PCR products were purified and cloned using the TOPO-TA cloning kit (Invitrogen). Inserts were Sangersequenced bidirectionally using M13 Forward and M13 Reverse vector primers following manufacturer's recommendations. A total of 411 nifH clone sequences were generated, among which 148 showed less than $95 \%$ nucleotide identity with any previously published sequence. These 148 sequences were grouped into clusters sharing more than $99 \%$ nucleotide identity and represented by 10 consensus sequences (Supplementary Data 3 ). The recA sequences were obtained from sequenced genomes in $\mathrm{IMG}^{93}$ and from OM-RGC-v2 ${ }^{22}$. Homologous sequences were included in the two catalogs as outgroups to minimize false-positive read alignments. These latter sequences were retrieved from IMG, OM-RGC-v2, and the Marine Microbial Eukaryotic Transcriptome Sequencing Project (MMETSP ${ }^{95}$ ) using HMMer v3.2.1 with gathering threshold option (http://hmmer.org/). The outgroups for $\operatorname{rec} A$ consisted of sequences coding for the RecA Pfam domain (PF00154), including RADA and RADB in Archaea, RAD51, and DCM1 in eukaryotes, and UvsX in viruses ${ }^{96}$. Outgroups for nifH consisted of sequences coding for the Pfam domain Fer4_NifH (PF00142), including a subunit of the pigment biosynthesis complexes protochlorophyllide reductase and chlorophyllide reductase ${ }^{97}$.

Phylogenetic analysis of recruited metagenomic reads. To support the taxonomic affiliation of metagenomic reads recruited by nifH sequences from 'spheroid bodies', we carried out a phylogenetic reconstruction in the following way. The translated metagenomic reads were aligned against a NifH reference alignment using the option --add of MAFFT version 6 with the G-INS-I strategy ${ }^{98}$. The resulting protein alignment was used for aligning the corresponding nucleotide sequences using Translator $\mathrm{X}^{99}$ and phylogenetic trees were generated using the HKY85 substitution model in PhyML version 3.0100. Four categories of rate variation were used. The starting tree was a BIONJ tree and the type of tree improvement was subtree pruning and regrafting. Branch support was calculated using the approximate likelihood ratio test (aLRT) with a Shimodaira-Hasegawalike (SH-like) procedure.

Flow cytometry data and analysis. For quantifying the densities of single-cel free-living diazotrophs, we combined the cell density measurements from flow cytometry with the relative abundances derived from molecular methods ${ }^{101}$. Specifically, we multiplied the bacterial concentration derived from flow cytometry by the nifH to $\mathrm{rec} A$ ratio of metagenomic read abundances from samples of size fraction $0.22-1.6 / 3 \mu \mathrm{m}$. For biovolume estimations of single-cell free-living diazotrophs, we assumed an average cell biovolume of $1 \mu \mathrm{m}^{3}$ based on the cell dimensions reported in literature for cultured NCDs ${ }^{102-107}$

The free-living bacterial densities were retrieved from the last version of the publicly available flow cytometry Tara Oceans dataset (https://doi.org/10.17632/ p9r9wttjkm.2), which were generated in the following way (see also refs. ${ }^{23,108}$ ). Briefly, three 1-mL seawater samples (pre-filtered through $200 \mu \mathrm{m}$ mesh) were collected from the three layers (surface, DCM, and mesopelagic) using the vertical profile sampling system (CTD-rosette). Cold $25 \%$ glutaraldehyde (final concentration of $0.125 \%$ ) was amended to each sample for $10 \mathrm{~min}$, which was held in the dark prior to flash freezing in liquid nitrogen, and long-term storage at $-80^{\circ} \mathrm{C}$ until analyses. Two subsamples $(400 \mu \mathrm{l})$ were stained with 1:10 SybrGreen 1 stock to a $2.5 \mu \mathrm{mol} \mathrm{L}^{-1}$ final concentration for enumerating the heterotrophic prokaryotes in separate counts. After 10 min of staining in the dark, each sample was loaded into a FACsCalibur (Becton and Dickinson, Franklin Lakes, NJ, USA) flow cytometer fitted with a 15-mW Argon-ion laser (4888-nm emission). A summary of the gating strategy is shown in Supplementary Fig. S13. Two populations of heterotrophic prokaryotes are distinguished: high and low containing DNA, by the combination of side scatter (SSC), as well as nucleic acid derived SybrGreen green fluorescence (FL1). A known density of fluorescent beads ( $1 \mu \mathrm{m}$, Fluoresbrite carboxylate microspheres, Polysciences, Inc., Warrington, PA USA) was used as an internal standard. The two other subsamples were not stained and used to enumerate phototrophic pico-phytoplankton, including

Prochlorococcus and Synechococcus. The latter were discriminated by gating on side scatter, chlorophyll content (FL3, red fluorescence), and phycoerythrin (FL2, orange fluorescence). A minimum of 30,000 events and on average 90,000 events were acquired for each subsample. Total abundance of prokaryotic cells was based on the abundances of heterotrophic prokaryotes and phototrophic prokaryotes. 
Detection of diazotrophs in the confocal laser-scanning microscopy dataset. We analyzed the quantitative microscopy images publicly available on the Ecotaxa web platform ${ }^{109}$. These images were generated using environmental High Content Fluorescence Microscopy (eHCFM) ${ }^{30}$ on (i) 61 samples collected at 48 different stations using a microplankton net $(20 \mu \mathrm{m}$ mesh size) and filtering the cod end volume through a $180 \mu \mathrm{m}$ sieve; (ii) 75 samples collected at 51 stations using a nanoplankton net ( $5 \mu$ mesh size) and filtering the coded volume through a $20 \mu \mathrm{m}$ sieve (Supplementary Fig. S2). Sample collection and preparation were, briefly, as follows: samples were fixed on board Tara in 10\% monomeric formaldehyde ( $1 \%$ final concentration) buffered at $\mathrm{pH} 7.5$ and $500 \mu \mathrm{EM}$ grade glutaraldehyde $(0.25 \%$ final concentration) and kept at $4{ }^{\circ} \mathrm{C}$ until analysis. Cells were imaged by Confocal Laser Scanning Microscopy (Leica Microsystem SP8, Leica Germany), equipped with several laser lines $(405,488,552,638 \mathrm{~nm})$. The 5-20 $\mu \mathrm{m}$ size fraction was imaged with the water immersion lens HC PL APO 40x/1,10 mot CORR CS2 objective, and the 20-180 $\mu \mathrm{m}$ size fraction was imaged with the HC PL APO 20x/ 0.75IMM CORR CS2 objective. Multiple fluorescent dyes were used to observe the cellular components of the organisms, including the nuclei (blue, Hoechst, Ex405 $\mathrm{nm} / \mathrm{Em} 420-470 \mathrm{~nm}$ ), cellular membranes (green, DiOC6(3), Ex488 nm/ Em500-520 nm), cell surface (cyan, AlexaFluor 546, Ex552 nm/Em560-590 nm), and chlorophyll autofluorescence (red, Ex638 nm/Em680-700 nm).

We used the confocal microscopy data to quantify DDAs and free filaments of Trichodesmium for abundance and biovolume. Image classification and annotation were carried out using the Ecotaxa web platform ${ }^{109}$ in the following way. We first manually searched for the target taxa and curated an initial training set in a few samples where molecular methods detected high abundances (i.e., high metagenomic read abundance of nifH), obtaining 55 images for DDAs and 39 for Trichodesmium filaments (Supplementary Data 5). This training set was then used for automating the classification of the whole dataset by means of supervised machine learning (random forest) based on a collection of 480 numeric 2D/3D feature ${ }^{30}$. The predictions were, in turn, manually curated and used as a new training set, repeating this step iteratively until no new images appeared. Other taxonomic groups were also annotated and used as outgroups to improve the predictions of our taxa of interest. Abundance estimates were normalized based on the total sample volumes as cells $\mathrm{L}^{-1}$ (see below). DDAs are enumerated as symbiotic cells $\mathrm{L}^{-1}$, while Trichodesmium are filaments $\mathrm{L}^{-1}$. We used the major and minor axis of every image to calculate their ellipsoidal equivalent biovolume.

Ploidy calculation for Trichodesmium and Richelia/Calothrix. For ploidy calculations, we used the paired confocal microscopy imaging and metagenomes obtained from the same $20-180-\mu \mathrm{m}$ size-fractionated samples, thus dividing the cells $\mathrm{L}^{-1}$ by the $n i f H$ copies $\mathrm{L}^{-1}$. A known volume of seawater $\left(V_{\text {seawater }} \mathrm{L}\right)$ was filtered and recorded through the plankton net $(20 \mu \mathrm{m}$ mesh). Contents of the cod end were filtered through a $180 \mu \mathrm{m}$ sieve and diluted to $3 \mathrm{~L}$. Forty-five milliliters of the diluted cod end was fixed with $5 \mathrm{ml}$ formaldehyde ( $1 \%$ final) and glutaraldehyde $(0.25 \% \text { final })^{30}$, and kept at $4{ }^{\circ} \mathrm{C}$. A subsample volume (Vi, liter) was mounted into an optical multi-well plate for automated confocal imaging and adjusted to avoid the saturation of the well bottom. The well bottom area $\left(86 \mathrm{~mm}^{2}\right)$ was fully imaged. The organisms were segmented from the images, and then identified and counted. Hence, the estimate of the abundance (A) per liter of a given biological group in the original seawater is provided by $\mathrm{A}=$ \#occurrence/ $(\mathrm{Vi} \times \mathrm{Cf})$; the concentration factor $\mathrm{Cf}=\left(V_{\text {seawater }} / 3 \mathrm{~L}\right) \times(45 / 50)$. The number of Richelia/Calothrix filaments per host and number cells per filament in Trichodesmium and Richelia/Calothrix were enumerated manually, thus obtaining the values of cells $\mathrm{L}^{-1}$ in each sample.

For nucleic acid isolation, $1000 \mathrm{~mL}$ were sampled from the diluted cod end and filtered onto $47-\mathrm{mm}$ diameter $10 \mu \mathrm{m}$ pore-size polycarbonate membrane filters (one to four membrane filters, $n$, depending on the sample), and immediately flashfrozen. DNA extraction was performed from one membrane as described by Alberti et al. ${ }^{24}$. Of the extracted DNA (DNA extracted, $\mathrm{ng}$ ), a quantity was used for DNA library preparation and sequencing process using Illumina machines (Illumina, USA $)^{24}$. Thus, we calculated the nifH copies $\mathrm{L}^{-1}$ for each taxa using the number of reads mapping the nifH reference sequences of the taxon of interest $\left(\operatorname{reads}_{\text {nifHtaxon }}\right)$ among the total number of sequenced reads $\left(\operatorname{reads}_{\text {total }}\right)$. We assumed $100 \%$ efficiency of DNA extraction for Trichodesmium and Richelia/Calothrix and a nifH gene length of $750 \mathrm{bp}$ (which implies $1.21 \times 10^{9}$ nifH copies/nifH ng). Hence, the estimate of the nifH copies (C) per liter of a given biological group in the original seawater is provided by $\mathrm{C}=\mathrm{DNA}_{\text {extracted }} *(1.21 \times$ $10^{9}$ copies $\left.n i f H / n g n i f H\right) * \operatorname{reads}_{n i f H t a x o n} / \operatorname{reads}_{\text {total }} /\left(V_{\text {seawater }} /(3 \mathrm{~L} * \mathrm{n})\right)$.

\section{Underwater Vision Profiler dataset and analysis. The Underwater Vision} Profiler 5 (UVP5, Hydroptics, France) ${ }^{33}$ is an underwater imager mounted on the Rosette Vertical Sampling System. This system illuminates precisely calibrated volumes of water and captures images during the descent $\left(5-20\right.$ images s $\left.^{-1}\right)$. The UVP5 was operated in situ and was designed to detect and count objects of $>100$ $\mu \mathrm{m}$ in length and to identify those of $>600 \mu \mathrm{m}$ in size. In the current work, we used this method for the quantification of Trichodesmium colony abundance and biovolume by mining the images publicly available on the Ecotaxa web platform ${ }^{109}$ The search, curation and annotation of the corresponding images and their biovolume determination were carried out as described in the previous section. Only images clearly curated as tuft or puff colonies were used to avoid false positives (fecal pellets, large diatom chains, etc). However, this stringent classification underestimated these colonies given the numerous stations without in situ UVP5 images annotated as Trichodesmium colonies but with detection of Trichodesmium nifH in the metagenomes of the $180-2000 \mu \mathrm{m}$ size-fractionated samples (Fig. 6c). This pattern can also be produced if Trichodesmium colonies do not pass the filter holes of $2000 \mu \mathrm{m}$ in diameter, but given that they are known to be fragile, it is probable that most of them pass it either undamaged or fragmented.

Determination of contextual physico-chemical parameters. Measurements of temperature were recorded at the time of sampling using the vertical profile sampling system (CTD-rosette) (https://doi.org/10.1594/PANGAEA.836319 and https://doi.org/10.1594/PANGAEA.836321). Dissolved nutrients $\left(\mathrm{NO}^{-}{ }_{3}, \mathrm{PO}_{4}\right)$ were analyzed according to previous methods ${ }^{110,111}$ with detection limits of 0.05 and $0.02 \mu \mathrm{mol} \mathrm{L}^{-1}$, respectively. Iron levels were derived from a global ocean biogeochemical model ${ }^{112}$. The datasets are listed in Supplementary Data 6.

Plotting and statistical analysis. Graphical analyses were carried out in $\mathrm{R}$ language (http://www.r-project.org/) using ggplot2 $2^{113}$ and treemaps were generated with treemap. Maps were generated with borders function in ggplot $2^{113}$ and geom_point function for bubbles or scatterpie ${ }^{114}$ package for pie charts. The trends between diazotroph abundance and latitude were displayed with generalized additive models using the geom_smooth function of ggplot $2^{113}$. Spearman's rho correlation coefficients and $p$-values were calculated using the cor.test function of the stats package. Metric multidimensional scaling (NMDS) analysis to visualize Bray-Curtis distances was carried out with the metaMDS command in the $\mathrm{R}$ package vegan ${ }^{115}$, and the influence of environmental variables on sample ordination was evaluated with the function envfit in the same R package, whereas the pie charts were plotted with scatterpie ${ }^{114}$ package. Hierarchical agglomerative clustering of samples using average linkage was performed with the function hclust of the R package stats.

Reporting summary. Further information on research design is available in the Nature Research Reporting Summary linked to this article.

\section{Data availability}

The authors declare that all the data supporting the findings of this study are publicly available in the following repositories and in the supplementary information files of this paper. The contextual data are available in Pangaea (www.pangaea.de) ${ }^{21}$ with the identifier https://doi.org/10.1594/PANGAEA.875582. Flow cytometry data ${ }^{23,108}$ are available in Mendeley Data (https://data.mendeley.com) with the identifier https://doi. org/10.17632/p9r9wttikm.2. The confocal microscopy ${ }^{30}$ and UVP5 ${ }^{33}$ images annotated as diazotrophs in the current work and their corresponding metadata were submitted to the EMBL-EBI repository BioStudies (www.ebi.ac.uk/biostudies) under accession SBSST529; while the whole image databases and their metadata are available at Ecotaxa (confocal microscopy of 5-20 $\mu \mathrm{m}$ sized-fractionated samples: https://ecotaxa.obs-vlfr.fr/ pri/3365; confocal microscopy of 20-180 $\mu \mathrm{m}$ sized-fractionated samples: https://ecotaxa. obs-vlfr.fr/pri/2274; UVP5: https://ecotaxa.obs-vlfr.fr/prj/579). Tara Oceans metagenomes $22,24,25$ are archived at ENA under the accession numbers: PRJEB1787, PRJEB1788, PRJEB4352, PRJEB4419, PRJEB9691, PRJEB9740, and PRJEB9742. The nifH and $r e c A$ catalogs were compiled from Integrated Microbial Genomes (IMG, https://img. jgi.doe.gov/); Marine Microbial Eukaryotic Transcriptome Sequencing Project (MMETSP; https://github.com/dib-lab/dib-MMETSP); OM-Reference Gene Catalog version 2 (OM-RGC-v2, https://www.ocean-microbiome.org/); Tara Oceans assemblies (Supplementary Table 8 from ref. ${ }^{16}$ ); and the nifH database (version April 2014) curated and hosted at Zehr Lab, University of California, Santa Cruz, CA, USA (https://www. jzehrlab.com/nifh). The 10 nifH sequences generated in the clone libraries of the current work were submitted to ENA under the accession numbers: MW590317MW590326. Source data are provided with this paper.

Received: 17 October 2020; Accepted: 8 June 2021; Published online: 06 July 2021

\section{References}

1. Field, C. B., Behrenfeld, M. J., Randerson, J. T. \& Falkowski, P. Primary production of the biosphere: integrating terrestrial and oceanic components. Science 281, 237-240 (1998).

2. Moore, C. M. et al. Processes and patterns of oceanic nutrient limitation. Nat. Geosci. 6, 701-710 (2013).

3. Tyrrell, T. The relative influences of nitrogen and phosphorus on oceanic primary production. Nature 400, 525-531 (1999).

4. Falkowski, P. G. Evolution of the nitrogen cycle and its influence on the biological sequestration of $\mathrm{CO}_{2}$ in the ocean. Nature 387, 272-275 (1997).

5. Karl, D. et al. The role of nitrogen fixation in biogeochemical cycling in the subtropical North Pacific Ocean. Nature 388, 533-538 (1997). 
6. Capone, D. G. et al. Nitrogen fixation by Trichodesmium spp.: an important source of new nitrogen to the tropical and subtropical North Atlantic Ocean. Glob. Biogeochem. Cycles 19, GB2024 (2005).

7. Capone, D. G. Trichodesmium, a globally significant marine cyanobacterium. Science 276, 1221-1229 (1997).

8. Moisander, P. H. et al. Unicellular cyanobacterial distributions broaden the oceanic $\mathrm{N}_{2}$ fixation domain. Science 327, 1512-1514 (2010).

9. Thompson, A. W. et al. Unicellular cyanobacterium symbiotic with a singlecelled eukaryotic alga. Science 337, 1546-1550 (2012).

10. Farnelid, H., Turk-Kubo, K., Muñoz-Marín, M. C. \& Zehr, J. P. New insights into the ecology of the globally significant uncultured nitrogen-fixing symbiont UCYN-A. Aquat. Microb. Ecol. 77, 125-138 (2016).

11. Cornejo-Castillo, F. M. et al. UCYN-A3, a newly characterized open ocean sublineage of the symbiotic $\mathrm{N}_{2}$-fixing cyanobacterium Candidatus Atelocyanobacterium thalassa. Environ. Microbiol. 21, 111-124 (2019).

12. Carpenter, E. J. \& Janson, S. Intracellular symbionts in the marine diatom Climacodium frauenfeldianum Grunow (Bacillariophyceae). J. Phycol. 36, 540-544 (2000).

13. Caputo, A., Nylander, J. A. A. \& Foster, R. A. The genetic diversity and evolution of diatom-diazotroph associations highlights traits favoring symbiont integration. FEMS Microbiol. Lett. 366, fnz120 (2019).

14. Webb, E. A., Ehrenreich, I. M., Brown, S. L., Valois, F. W. \& Waterbury, J. B. Phenotypic and genotypic characterization of multiple strains of the diazotrophic cyanobacterium, Crocosphaera watsonii, isolated from the open ocean. Environ. Microbiol. 11, 338-348 (2009).

15. Foster, R. A. et al. Influence of the Amazon River plume on distributions of free-living and symbiotic cyanobacteria in the western tropical north Atlantic Ocean. Limnol. Oceanogr. 52, 517-532 (2007).

16. Delmont, T. O. et al. Nitrogen-fixing populations of Planctomycetes and Proteobacteria are abundant in surface ocean metagenomes. Nat. Microbiol. 3, 804-813 (2018).

17. Moisander, P. H. et al. Chasing after non-cyanobacterial nitrogen fixation in marine pelagic environments. Front. Microbiol. 8, 1736 (2017)

18. Farnelid, H. et al. Nitrogenase gene amplicons from global marine surface waters are dominated by genes of non-cyanobacteria. PLoS ONE 6, e19223 (2011).

19. Luo, Y.-W. et al. Database of diazotrophs in global ocean: abundance, biomass and nitrogen fixation rates. Earth Syst. Sci. Data 4, 47-73 (2012).

20. Tang, W. \& Cassar, N. Data-driven modeling of the distribution of diazotrophs in the global ocean. Geophys. Res. Lett. 46, 12258-12269 (2019).

21. Pesant, S. et al. Open science resources for the discovery and analysis of Tara Oceans data. Sci. Data 2, 150023 (2015).

22. Salazar, G. et al. Gene expression changes and community turnover differentially shape the global ocean metatranscriptome. Cell 179, 1068-1083. e21 (2019).

23. Sunagawa, S. et al. Structure and function of the global ocean microbiome. Science 348, 1261359 (2015).

24. Alberti, A. et al. Viral to metazoan marine plankton nucleotide sequences from the Tara Oceans expedition. Sci. Data 4, 170093 (2017)

25. Carradec, Q. et al. A global ocean atlas of eukaryotic genes. Nat. Commun. 9, 373 (2018).

26. Cornejo-Castillo, F. M. et al. Cyanobacterial symbionts diverged in the late Cretaceous towards lineage-specific nitrogen fixation factories in single-celled phytoplankton. Nat. Commun. 7, 11071 (2016).

27. Cornejo-Castillo, F. M. \& Zehr, J. P. Intriguing size distribution of the uncultured and globally widespread marine non-cyanobacterial diazotroph Gamma-A. ISME J. 15, 124-128 (2020).

28. Vorobev, A. et al. Transcriptome reconstruction and functional analysis of eukaryotic marine plankton communities via high-throughput metagenomics and metatranscriptomics. Genome Res. 30, 647-659 (2020).

29. Güell, M., Yus, E., Lluch-Senar, M. \& Serrano, L. Bacterial transcriptomics: what is beyond the RNA horiz-ome? Nat. Rev. Microbiol. 9, 658-669 (2011).

30. Colin, S. et al. Quantitative 3D-imaging for cell biology and ecology of environmental microbial eukaryotes. Elife 6, e26066 (2017).

31. Cabello, A. M. et al. Global distribution and vertical patterns of a prymnesiophyte-cyanobacteria obligate symbiosis. ISME J. 10, 693-706 (2016).

32. Sunagawa, S. et al. Metagenomic species profiling using universal phylogenetic marker genes. Nat. Methods 10, 1196-1199 (2013).

33. Picheral, M. et al. The Underwater Vision Profiler 5: an advanced instrument for high spatial resolution studies of particle size spectra and zooplankton. Limnol. Oceanogr.: Methods 8, 462-473 (2010).

34. Tenório, M. M. B., Dupouy, C., Rodier, M. \& Neveux, J. Trichodesmium and other planktonic cyanobacteria in New Caledonian waters (SW tropical Pacific) during an El Niño episode. Aquat. Microb. Ecol. 81, 219-241 (2018).

35. Gómez, F., Furuya, K. \& Takeda, S. Distribution of the cyanobacterium Richelia intracellularis as an epiphyte of the diatom Chaetoceros compressus in the western Pacific Ocean. J. Plankton Res. 27, 323-330 (2005).
36. Villareal, T. A. Laboratory culture and preliminary characterization of the nitrogen-fixing Rhizosolenia-Richelia symbiosis. Mar. Ecol. 11, 117-132 (1990).

37. Foster, R. A., Goebel, N. L. \& Zehr, J. P. Isolation of Calothrix rhizosoleniae (cyanobacteria) strain SC01 from Chaetoceros (Bacillariophyta) spp. diatoms of the Subtropical North Pacific Ocean. J. Phycol. 46, 1028-1037 (2010).

38. Karl, D. M., Church, M. J., Dore, J. E., Letelier, R. M. \& Mahaffey, C. Predictable and efficient carbon sequestration in the North Pacific Ocean supported by symbiotic nitrogen fixation. Proc. Natl Acad. Sci. USA 109, 1842-1849 (2012)

39. Scharek, R., Tupas, L. M. \& Karl, D. M. Diatom fluxes to the deep sea in the oligotrophic North Pacific gyre at Station ALOHA. Mar. Ecol. Prog. Ser. 182, 55-67 (1999).

40. Scharek, R., Latasa, M., Karl, D. M. \& Bidigare, R. R. Temporal variations in diatom abundance and downward vertical flux in the oligotrophic North Pacific gyre. Deep Sea Res. Part I Oceanogr. Res. Pap. 46, 1051-1075 (1999).

41. Ratten, J.-M. et al. Sources of iron and phosphate affect the distribution of diazotrophs in the North. Atl. Deep Sea Res. Part II Top. Stud. Oceanogr. 116, 332-341 (2015).

42. Tzubari, Y., Magnezi, L., Be'er, A. \& Berman-Frank, I. Iron and phosphorus deprivation induce sociality in the marine bloom-forming cyanobacterium. Trichodesmium. ISME J. 12, 1682-1693 (2018).

43. Geisler, E., Bogler, A., Rahav, E. \& Bar-Zeev, E. Direct detection of heterotrophic diazotrophs associated with planktonic aggregates. Sci. Rep. 9, 9288 (2019).

44. Bentzon-Tilia, M., Severin, I., Hansen, L. H. \& Riemann, L. Genomics and ecophysiology of heterotrophic nitrogen fixing bacteria isolated from estuarine surface water. mBio 6, e929-15 (2015).

45. Scavotto, R. E., Dziallas, C., Bentzon-Tilia, M., Riemann, L. \& Moisander, P. H. Nitrogen-fixing bacteria associated with copepods in coastal waters of the North Atlantic Ocean. Environ. Microbiol. 17, 3754-3765 (2015).

46. Foster, R. A. \& Zehr, J. P. Diversity, genomics, and distribution of phytoplankton-cyanobacterium single-cell symbiotic associations. Annu. Rev. Microbiol. 73, 435-456 (2019).

47. Tripp, H. J. et al. Metabolic streamlining in an open-ocean nitrogen-fixing cyanobacterium. Nature 464, 90-94 (2010).

48. Farnelid, H. et al. Diverse diazotrophs are present on sinking particles in the North Pacific Subtropical Gyre. ISME J. 13, 170-182 (2019).

49. Drum, R. W. \& Pankratz, S. Fine structure of an unusual cytoplasmic inclusion in the diatom genus. Rhopalodia. Protoplasma 60, 141-149 (1965).

50. Nakayama, T. \& Inagaki, Y. Genomic divergence within non-photosynthetic cyanobacterial endosymbionts in rhopalodiacean diatoms. Sci. Rep. 7, 13075 (2017).

51. Prechtl, J., Kneip, C., Lockhart, P., Wenderoth, K. \& Maier, U.-G. Intracellular spheroid bodies of Rhopalodia gibba have nitrogen-fixing apparatus of cyanobacterial origin. Mol. Biol. Evol. 21, 1477-1481 (2004).

52. Nakayama, T. et al. Complete genome of a nonphotosynthetic cyanobacterium in a diatom reveals recent adaptations to an intracellular lifestyle. Proc. Natl Acad. Sci. USA 111, 11407-11412 (2014).

53. Patrick, R. \& Reimer, C. W. The diatoms of the United States: exclusive of Alaska and Hawaii. Volume 2, Part 1, Entomoneidaceae, Cymbellaceae, Gomphonemaceae, Epithemiaceae (1975).

54. Stancheva, R. et al. Nitrogen-fixing cyanobacteria (free-living and diatom endosymbionts): their use in southern California stream bioassessment. Hydrobiologia 720, 111-127 (2013).

55. Maldonado, R., Jimenez, J. \& Casadesus, J. Changes of ploidy during the Azotobacter vinelandii growth cycle. J. Bacteriol. 176, 3911-3919 (1994).

56. Simon, R. D. Macromolecular composition of spores from the filamentous cyanobacterium Anabaena cylindrica. J. Bacteriol. 129, 1154-1155 (1977).

57. Simon, R. D. DNA content of heterocysts and spores of the filamentous cyanobacterium Anabaena variabilis. FEMS Microbiol. Lett. 8.4, 241-245 (1980).

58. Griese, M., Lange, C. \& Soppa, J. Ploidy in cyanobacteria. FEMS Microbiol. Lett. 323, 124-131 (2011).

59. Sukenik, A., Kaplan-Levy, R., Welch, J. \& Post, A. F. Massive multiplication of genome and ribosomes in dormant cells (akinetes) of Aphanizomenon ovalisporum (Cyanobacteria). ISME J. 6, 670-679 (2012).

60. Sargent, E. C. et al. Evidence for polyploidy in the globally important diazotroph. Trichodesmium. FEMS Microbiol. Lett. 363, fnw244 (2016).

61. Dutkiewicz, S., Ward, B. A., Monteiro, F. \& Follows, M. J. Interconnection of nitrogen fixers and iron in the Pacific Ocean: Theory and numerical simulations. Glob. Biogeochem. Cycles 26, GB1012 (2012).

62. Deutsch, C., Sarmiento, J. L., Sigman, D. M., Gruber, N. \& Dunne, J. P. Spatial coupling of nitrogen inputs and losses in the ocean. Nature 445, 163-167 (2007).

63. Mills, M. M., Ridame, C., Davey, M., La Roche, J. \& Geider, R. J. Iron and phosphorus co-limit nitrogen fixation in the eastern tropical North Atlantic. Nature 429, 292-294 (2004). 
64. Raven, J. A. The iron and molybdenum use efficiencies of plant growth with different energy, carbon and nitrogen sources. N. Phytol. 109, 279-287 (1988).

65. Kustka, A. B. et al. Iron requirements for dinitrogen- and ammoniumsupported growth in cultures of Trichodesmium (IMS 101): Comparison with nitrogen fixation rates and iron: carbon ratios of field populations. Limnol. Oceanogr. 48, 1869-1884 (2003).

66. Subramaniam, A. et al. Amazon River enhances diazotrophy and carbon sequestration in the tropical North Atlantic Ocean. Proc. Natl Acad. Sci. U. S. A. 105, 10460-10465 (2008).

67. Walsby, A. E. Marine Pelagic Cyanobacteria: Trichodesmium and Other Diazotrophs, 141-161 (Springer Netherlands, 1992).

68. Rouco, M. et al. Variable depth distribution of Trichodesmium clades in the North Pacific Ocean. Environ. Microbiol. Rep. 8, 1058-1066 (2016).

69. Pabortsava, K. et al. Carbon sequestration in the deep Atlantic enhanced by Saharan dust. Nat. Geosci. 10, 189-194 (2017).

70. Foster, R. A., Sztejrenszus, S. \& Kuypers, M. M. M. Measuring carbon and $\mathrm{N}_{2}$ fixation in field populations of colonial and free-living unicellular cyanobacteria using nanometer-scale secondary ion mass spectrometry. $J$. Phycol. 49, 502-516 (2013).

71. Brown, S. M. \& Jenkins, B. D. Profiling gene expression to distinguish the likely active diazotrophs from a sea of genetic potential in marine sediments. Environ. Microbiol. 16, 3128-3142 (2014).

72. Caputi, L. et al. Community-level responses to iron availability in open ocean plankton ecosystems. Glob. Biogeochem. Cycles 33, 391-419 (2019).

73. Loescher, C. R. et al. Facets of diazotrophy in the oxygen minimum zone waters off Peru. ISME J. 8, 2180-2192 (2014).

74. Fernandez, C., Farías, L. \& Ulloa, O. Nitrogen fixation in denitrified marine waters. PLoS ONE 6, e20539 (2011).

75. Jayakumar, A., Al-Rshaidat, M. M. D., Ward, B. B. \& Mulholland, M. R. Diversity, distribution, and expression of diazotroph nifH genes in oxygendeficient waters of the Arabian Sea. FEMS Microbiol. Ecol. 82, 597-606 (2012).

76. Turk-Kubo, K. A., Karamchandani, M., Capone, D. G. \& Zehr, J. P. The paradox of marine heterotrophic nitrogen fixation: abundances of heterotrophic diazotrophs do not account for nitrogen fixation rates in the Eastern Tropical South Pacific. Environ. Microbiol. 16, 3095-3114 (2014).

77. Jayakumar, A. et al. Biological nitrogen fixation in the oxygen-minimum region of the eastern tropical North Pacific ocean. ISME J. 11, 2356-2367 (2017).

78. Kimor, B. \& Golandsky, B. Microplankton of the Gulf of Elat: aspects of seasonal and bathymetric distribution. Mar. Biol. 42, 55-67 (1977).

79. Gordon, N., Angel, D. L., Neorl, A., Kress, N. \& Kimor, B. Heterotrophic dinoflagellates with symbiotic cyanobacteria and nitrogen limitation in the Gulf of Aqaba. Mar. Ecol. Prog. Ser. 107, 83-88 (1994)

80. Post, A. F. et al. Spatial and temporal distribution of Trichodesmium spp. in the stratified Gulf of Aqaba, Red Sea. Mar. Ecol. Prog. Ser. 239, 241-250 (2002).

81. Foster, R. A., Paytan, A. \& Zehr, J. P. Seasonality of $\mathrm{N}_{2}$ fixation and $n i f H$ gene diversity in the Gulf of Aqaba (Red Sea). Limnol. Oceanogr. 54, 219-233 (2009).

82. Lannes, R., Olsson-Francis, K., Lopez, P. \& Bapteste, E. Carbon fixation by marine ultrasmall prokaryotes. Genome Biol. Evol. 11, 1166-1177 (2019).

83. Pati, A. et al. Complete genome sequence of Arcobacter nitrofigilis type strain (CI). Stand. Genom. Sci. 2, 300-308 (2010).

84. Belgrano, A., Allen, A. P., Enquist, B. J. \& Gillooly, J. F. Allometric scaling of maximum population density: a common rule for marine phytoplankton and terrestrial plants. Ecol. Lett. 5, 611-613 (2002).

85. Gaby, J. C. \& Buckley, D. H. The use of degenerate primers in qPCR analysis of functional genes can cause dramatic quantification bias as revealed by investigation of nifH primer performance. Microb. Ecol. 74, 701-708 (2017).

86. Kembel, S. W., Wu, M., Eisen, J. A. \& Green, J. L. Incorporating $16 \mathrm{~S}$ gene copy number information improves estimates of microbial diversity and abundance. PLoS Comput. Biol. 8, e1002743 (2012).

87. Angly, F. E. et al. CopyRighter: a rapid tool for improving the accuracy of microbial community profiles through lineage-specific gene copy number correction. Microbiome 2, 11 (2014).

88. Zehr, J. P., Mellon, M. T. \& Hiorns, W. D. Phylogeny of cyanobacterial nifH genes: evolutionary implications and potential applications to natural assemblages. Microbiology 143, 1443-1450 (1997).

89. Thiel, T. \& Pratte, B. S. Regulation of three nitrogenase gene clusters in the cyanobacterium Anabaena variabilis ATCC 29413. Life 4, 944-967 (2014).

90. Langlois, R. J., Hümmer, D. \& LaRoche, J. Abundances and distributions of the dominant nifH phylotypes in the Northern Atlantic Ocean. Appl. Environ. Microbiol. 74, 1922-1931 (2008).

91. Li, H. \& Durbin, R. Fast and accurate short read alignment with BurrowsWheeler transform. Bioinformatics 25, 1754-1760 (2009).

92. Fu, L., Niu, B., Zhu, Z., Wu, S. \& Li, W. CD-HIT: accelerated for clustering the next-generation sequencing data. Bioinformatics 28, 3150-3152 (2012).

93. Chen, I.-M. A. et al. IMG/M v.5.0: an integrated data management and comparative analysis system for microbial genomes and microbiomes. Nucleic Acids Res. 47, D666-D677 (2019).
94. Zehr, J. P. \& Turner, P. J. in Methods in Microbiology 271-286 (Elsevier, 2001)

95. Keeling, P. J. et al. The Marine Microbial Eukaryote Transcriptome Sequencing Project (MMETSP): illuminating the functional diversity of eukaryotic life in the oceans through transcriptome sequencing. PLoS Biol. 12, e1001889 (2014).

96. Lin, Z., Kong, H., Nei, M. \& Ma, H. Origins and evolution of the recA/RAD51 gene family: evidence for ancient gene duplication and endosymbiotic gene transfer. Proc. Natl Acad. Sci. USA 103, 10328-10333 (2006).

97. Fujita, Y. \& Bauer, C. E. Reconstitution of light-independent protochlorophyllide reductase from purified bchl and BchN-BchB subunits. In vitro confirmation of nitrogenase-like features of a bacteriochlorophyll biosynthesis enzyme. J. Biol. Chem. 275, 23583-23588 (2000).

98. Katoh, K. \& Toh, H. Improved accuracy of multiple ncRNA alignment by incorporating structural information into a MAFFT-based framework. BMC Bioinforma. 9, 212 (2008).

99. Abascal, F., Zardoya, R. \& Telford, M. J. TranslatorX: multiple alignment of nucleotide sequences guided by amino acid translations. Nucleic Acids Res. $\mathbf{3 8}$, W7-W13 (2010).

100. Guindon, S. et al. New algorithms and methods to estimate maximumlikelihood phylogenies: assessing the performance of PhyML 3.0. Syst. Biol. 59, 307-321 (2010).

101. Props, R. et al. Absolute quantification of microbial taxon abundances. ISME J. 11, 584-587 (2017).

102. Distel, D. L., Morrill, W., MacLaren-Toussaint, N., Franks, D. \& Waterbury, J. Teredinibacter turnerae gen. nov., sp. nov., a dinitrogen-fixing, cellulolytic, endosymbiotic gamma-proteobacterium isolated from the gills of woodboring molluscs (Bivalvia: Teredinidae). Int. J. Syst. Evol. Microbiol. 52, 2261-2269 (2002).

103. Lalucat, J., Bennasar, A., Bosch, R., García-Valdés, E. \& Palleroni, N. J. Biology of Pseudomonas stutzeri. Microbiol. Mol. Biol. Rev. 70, 510-547 (2006).

104. Inomura, K., Bragg, J. \& Follows, M. J. A quantitative analysis of the direct and indirect costs of nitrogen fixation: a model based on Azotobacter vinelandii. ISME J. 11, 166-175 (2017).

105. Romanenko, L. A., Tanaka, N., Svetashev, V. I. \& Falsen, E. Description of Cobetia amphilecti sp. nov., Cobetia litoralis sp. nov. and Cobetia pacifica sp. nov., classification of Halomonas halodurans as a later heterotypic synonym of Cobetia marina and emended descriptions of the genus Cobetia and Cobetia marina. Int. J. Syst. Evol. Microbiol. 63, 288-297 (2013).

106. Ramana, V. V. et al. Descriptions of Rhodopseudomonas parapalustris sp. nov., Rhodopseudomonas harwoodiae sp. nov. and Rhodopseudomonas pseudopalustris sp. nov., and emended description of Rhodopseudomonas palustris. Int. J. Syst. Evol. Microbiol. 62, 1790-1798 (2012).

107. Alfaro-Espinoza, G. \& Ullrich, M. S. Marinobacterium mangrovicola sp. nov., a marine nitrogen-fixing bacterium isolated from mangrove roots of Rhizophora mangle. Int. J. Syst. Evol. Microbiol. 64, 3988-3993 (2014).

108. Hingamp, P. et al. Exploring nucleo-cytoplasmic large DNA viruses in Tara Oceans microbial metagenomes. ISME J. 7, 1678-1695 (2013).

109. Picheral, M., Colin, S. \& Irisson, J.-O. EcoTaxa, a tool for the taxonomic classification of images. http://ecotaxa.obs-vlfr.fr (2017).

110. Murphy, J. \& Riley, J. P. A modified single solution method for the determination of phosphate in natural waters. Anal. Chim. Acta 27, 31-36 (1962).

111. Bendschneider, K. \& Robinson, R. J. A new spectrophotometric method for the determination of nitrite in sea water. J. Mar. Res. 11, 87-96 (1952).

112. Aumont, O., Ethé, C., Tagliabue, A., Bopp, L. \& Gehlen, M. PISCES-v2: an ocean biogeochemical model for carbon and ecosystem studies. Geosci. Model Dev. 8, 2465-2513 (2015).

113. Wickham, H. ggplot2: Elegant Graphics for Data Analysis (Springer Science \& Business Media, 2009)

114. Yu, G. scatterpie: Scatter pie plot. https://CRAN.R-project.org/ package $=$ scatterpie (2018)

115. Oksanen, J. et al. vegan: Community ecology package. https://cran.r-project. org/web/packages/vegan/index.html (2019).

\section{Acknowledgements}

We would like to thank all colleagues from the Tara Oceans consortium as well as the Tara Ocean Foundation for their inspirational vision. We also acknowledge the current and past members of the laboratory of JP Zehr for the curation and public access to the nifH database. We are grateful to Lionel Guidi, Stéphane Pesant, and Julie Poulain for providing details about Tara Oceans sampling, Luca Santangeli from EMBL Heidelberg for confocal microscopy image acquisition and Luis Pedro Coelho (currently at Fudan University) for image processing, Benjamin Blanc from Laboratoire d'Océanographie de Villefranche-sur-mer for help with UVP5 image processing and annotation, Josep Gasol from Institut de Ciències del Mar-CSIC for expertise and assistance with flow cytometry, Daniel Lundin from Linnaeus University for his analytical support and advice, Tom Delmont from Genoscope for useful discussions, Flora Vincent from Weizmann Institute 
of Science for her help with Ecotaxa resource, Eric Bapteste, Philippe Lopez and Romain Lannes from Sorbonne Université for their advice with ultrasmall bacteria analysis. This work has been supported by the FFEM - French Facility for Global Environment, French Government 'Investissements d'Avenir' programs OCEANOMICS (ANR-11-BTBR0008), FRANCE GENOMIQUE (ANR-10-INBS-09-08), MEMO LIFE (ANR-10-LABX54), and PSL Research University (ANR-11-IDEX-0001-02). R.A.F. acknowledges funding from Knut and Alice Wallenberg foundation. C.B. acknowledges funding from the European Research Council (ERC) under the European Union's Horizon 2020 research and innovation program (Diatomic; grant agreement No. 835067) and Agence Nationale de la Recherche "Phytomet" (ANR-16-CE01-0008) projects. F.M.C.-C. acknowledges funding from the European Union's Horizon 2020 research program under the Marie Sklodowska-Curie grant agreement No. 749380 (UCYN2PLAST). S.G.A. acknowledges funding from the project "MAGGY" (CTM2017-87736-R) from the Spanish Ministry of Economy and Competitiveness and the 'Severo Ochoa Centre of Excellence' accreditation (CEX2019-000928-S). J.J.P.K. acknowledges postdoctoral funding from the Fonds Français pour l'Environnement Mondial. This article is contribution number 118 of Tara Oceans.

\section{Author contributions}

R.A.F. and C.B. designed the study and supervised the project. R.A.F., C.B., and J.J.P.K. wrote the paper with substantial input from all co-authors. J.J.P.K. compiled the marker gene catalogs and E.P. and P.W. performed the metagenomic mapping. R.P., S.C., C.d.V., and E.K. set up the imaging platform for the eHCFM data generation and processing. J.J. P.K., R.A.F., M.C., E.D., F.L., and S.C. performed the taxonomic annotation of the eHCFM dataset. F.M.C.-C. and S.G.A. generated the nifH clone libraries. M.P. performed the collection and taxonomic annotation of UVP5 dataset. J.J.P.K. performed the formal analysis and visualization.

\section{Funding}

Open access funding provided by Stockholm University.

\section{Competing interests}

The authors declare no competing interests.

\section{Additional information}

Supplementary information The online version contains supplementary material available at https://doi.org/10.1038/s41467-021-24299-y.

Correspondence and requests for materials should be addressed to C.B. or R.A.F.

Peer review information Nature Communications thanks the anonymous reviewer(s) for their contribution to the peer review of this work. Peer reviewer reports are available.

Reprints and permission information is available at http://www.nature.com/reprints

Publisher's note Springer Nature remains neutral with regard to jurisdictional claims in published maps and institutional affiliations.

(c) Open Access This article is licensed under a Creative Commons BY Attribution 4.0 International License, which permits use, sharing adaptation, distribution and reproduction in any medium or format, as long as you give appropriate credit to the original author(s) and the source, provide a link to the Creative Commons license, and indicate if changes were made. The images or other third party material in this article are included in the article's Creative Commons license, unless indicated otherwise in a credit line to the material. If material is not included in the article's Creative Commons license and your intended use is not permitted by statutory regulation or exceeds the permitted use, you will need to obtain permission directly from the copyright holder. To view a copy of this license, visit http://creativecommons.org/ licenses/by/4.0/.

(C) The Author(s) 2021 